\title{
O eclipse de Sobral e a deflexão gravitacional da luz predita por Einstein
}

\author{
Oscar T. Matsuura \\ Prof. Dr. - pesquisador e colaborador do MAST/MCTI \\ oscarmatsuura@gmail.com
}

Como citar este artigo: Matsuura, Oscar T. “O eclipse de Sobral e a deflexão gravitacional da luz predita por Einstein”. Khronos, Revista de História da Ciência, n 7, pp. 81-139. 2019. Disponível em <http://revistas.usp.br/khronos>. Acesso em dd/mm/aaaa.

Resumo: Este artigo é comemorativo do centenário do eclipse total do Sol ocorrido em 29/5/1919, cujos dados observacionais coletados por duas equipes britânicas deram lugar a um fato marcante da História da Ciência: a confirmação da deflexão da luz pelo Sol predita por Einstein, o que o entronizou da noite para o dia no panteão dos gênios da humanidade; e o lançamento ao mundo da Teoria da Relatividade Geral. Mas esse eclipse diz respeito especialmente a nós, brasileiros, pois foi observado por uma das equipes britânicas em Sobral, CE. Para o bom entendimento desse acontecimento, a curiosa ideia de que a luz pode deixar de caminhar em linha reta, será discutida desde seus primeiros registros. A formulação dessa ideia seguiu pari passu a elaboração da Relatividade Geral, ou melhor, a transição da Relatividade Restrita de 1905 à Relatividade Geral de 1915. A possibilidade da detecção num eclipse da deflexão da luz, um dos testes da validade da Relatividade Geral, mobilizou astrônomos de vários países por muitos anos. No eclipse de 1919 foi anunciada bombasticamente a confirmação da deflexão da luz e a validação da Relatividade Geral. Nesta parte, também visando o bom entendimento, o presente trabalho é suplementado com esclarecimentos sobre termos técnicos e sobre procedimentos de observação fotográfica e análise de imagens. A discussão e a proclamação dos resultados e a posterior "supercomprovação" da deflexão da luz serão discutidas à luz dos estudos de astrônomos e físicos, historiadores e filósofos da ciência realizados nestes 100 anos desde o eclipse, com o intuito de propor ao leitor uma reflexão, não só sobre os avanços conceituais e tecnológicos da ciência, mas sobretudo sobre as novas avaliações acerca da validade do conhecimento científico, da incidência dos fatores sociológicos e menos racionais na construção desse conhecimento. Nos bastidores da comunidade científica o anúncio bombástico dos resultados do eclipse de 1919 não foi simples e direto como as manchetes da época e algumas atuais, ainda insistem em nos fazer crer. Esta é a oportunidade para uma retificação, em benefício de uma percepção realista e não falsamente idealizada da ciência e dos cientistas.

Palavras-chave: deflexão gravitacional da luz, Relatividade Geral, eclipse solar, fotografia astronômica, lentes gravitacionais, Cosmologia 


\title{
The Sobral eclipse and the gravitational bending of light predicted by Einstein
}

\begin{abstract}
This article is for celebrating the centennial of the total eclipse of the Sun on May 29, 1919, which observational data collected by two British teams gave rise to a remarkable milestone of the History of Science: the confirmation of the deflection of light by the Sun, predicted by Einstein, that enthroned him overnight in the pantheon of the geniuses of the mankind; and the launch of General Relativity Theory into the world. But this eclipse concerns especially to us, Brazilians, as it was observed by one of the British teams in Sobral, CE. For the good understanding of this event, the curious idea that light can stop walking straight, will be discussed from its earliest records. The formulation of this idea followed step by step the construction of the General Relativity, or rather the transition from the Restricted Relativity of 1905 to the General Relativity of 1915. The possibility of the detection during an eclipse of the deflection of light, one of the tests of the validity of the General Relativity, aroused the interest of astronomers from many countries for many years. In the eclipse of 1919, the confirmation of the deflection of light and the validation of General Relativity was boastfully announced. Again, for the good understanding, this part of this paper will be supplemented with a clarification of the technical terms and procedures for photographic observation and image analysis. The discussion and the announcement of the results and the "super-proof" of the deflection of light achieved after decades, will be discussed in the light of the studies made by astronomers and physicists, as well as historians and philosophers of science in these 100 years since the eclipse, intending to propose to the readers a reflection, not only on the conceptual and technological advances of science, but especially on the new assessments of the validity of scientific knowledge, the incidence of sociological and less rational factors in the building of this knowledge. Behind the scenes of the scientific community, the bombastic announcement of the 1919 eclipse results was not as straightforward as the headlines of the epoch and some of the current headlines still insist. The centennial is an opportunity for an amendment for the sake of a realistic and not falsely idealized perception of the science and the scientists.
\end{abstract}

Keywords: gravitational bending of light, General Relativity, solar eclipse, astronomical photography, gravitational lens, Cosmology.

\section{Nem sempre a luz caminha em linha reta}

Aprendemos que a luz se propaga em linha reta, mas isso é no vácuo, assim como em meios materiais homogêneos e não opacos. Mesmo na convergência ou divergência de um feixe de raios luminosos com uma lente, ou pela reflexão na superfície de um espelho, os raios mudam bruscamente de direção na superfície da lente ou do espelho. A convergência ou divergência ocorre por causa da curvatura imposta às superfícies mas, em cada meio homogêneo a luz caminha em linha reta. 
Mas a Astronomia, que envolve escalas muito maiores que as escalas terrestres, pode tornar perceptível que a luz nem sempre caminhe em linha reta. A ideia seminal da deflexão da luz remonta ao próprio Isaac Newton (1643-1727), pai da Gravitação Universal. Em 1704, nas conclusões de seu tratado intitulado Opticks (NEWTON, 1952, p. 339)1 ${ }^{1}$, ele propôs a seguinte questão: Query 1. Do not Bodies act upon Light at a distance, and by their action bend its Rays; and is not this action (caeteris paribus) strongest at the least distance?

Aí a possibilidade da deflexão da luz já está colocada. A partir da teoria corpuscular da luz (que Newton defendia) e das leis da Mecânica e Gravitação de Newton, legitimamente se podia esperar que um raio de luz fosse desviado ao passar pelas proximidades de um objeto massivo, presumindo-se que os corpúsculos de luz respondessem à aceleração gravitacional, da mesma forma que os corpúsculos de matéria. Se ele já soubesse que os fótons não têm massa de repouso, esse raciocínio seria incoerente. Mas Newton não sabia disso. De qualquer forma, ele não aprofundou essa ideia, certamente não porque tivesse se intimidado com a matemática envolvida, mas por considerar o efeito tão diminuto que, na prática, passaria como se não existisse.

Talvez a primeira comunicação aplicando a ideia da deflexão da luz a estrelas, tenha sido feita 80 anos depois, pelo pastor e filósofo natural inglês de muita imaginação, John Michell (1724-1783) à Royal Society (RS) of London (SCHAFFER, 1979, p. 42)2. Ele se baseava na teoria corpuscular da luz e na noção decorrente da teoria de Newton, de velocidade de escape ${ }^{3}$. Assim, se o Sol mantivesse sua densidade média, mas fosse 500 vezes maior, a luz emitida radialmente retornaria à sua superfície após sofrer uma deflexão de $180^{\circ}$. Ainda segundo Michell, teríamos então uma “estrela obscura”, isto é, invisível. Essas estrelas obscuras já prefiguravam o que hoje chamamos buracos negros ${ }^{4}$ (SCHAFFER, 1979) ${ }^{5}$, explicados pela Relatividade Geral de Einstein como deformação extrema do espaço-tempo (ver adiante) por uma concentração extrema de matéria. Tanto a ideia de Michell, como ele próprio, permaneceram quase despercebidos e só saíram do limbo na década de 1970 quando um primeiro buraco negro foi detectado por um telescópio espacial de raios X, fazendo parte de um sistema estelar binário. Mas o que importa aqui, mais que o conceito de buraco negro, é a ideia da deflexão gravitacional da luz.

O primeiro cálculo da deflexão gravitacional da luz teria sido feito em 1801 pelo físico, matemático e astrônomo alemão Johann Georg von Soldner (1776-1833). Ele considerou um

${ }^{1}$ NEWTON, Sir Isaac. Opticks: A Treatise of the Reflections, Refractions, Inflections \& Colours of Light. New York: Dover Publications, Inc. 1952, p. 339.

2 SCHAFFER, Simon. John Michell and Black Holes (Note). Journal for the History of Astronomy, v. 10, p. 4243, 1979.

${ }^{3}$ Velocidade de escape é a velocidade mínima para que um objeto lançado verticalmente para cima, p. ex., da superfície da Terra, viaje indefinidamente, libertada da atração gravitacional da Terra (desconsiderandose a resistência do ar). Na superfície da Terra a velocidade de escape é $11,2 \mathrm{~km} / \mathrm{s}$. Com velocidade menor, o corpo lançado para cima perde velocidade até que esta se anula quando, então, o corpo inverte o sentido do movimento para cair na Terra. Essa inversão do movimento envolveria a deflexão da luz.

${ }^{4}$ Usarei itálico para grafar termos ou expressões técnicas quando aparecem pela primeira vez.

${ }^{5}$ SCHAFFER, Simon. Ibid., 1979. 
raio de luz rasante à superfície de um corpo, cuja ação gravitacional exercida a distância por uma força central, como pensava Newton, o desviaria da trajetória retilínea. Considerando a grande velocidade da luz, muito maior que a velocidade de escape do corpo em questão e, visando comodidade no cálculo, ignorou a sua variação. O cálculo não depende do valor da massa da partícula de luz e Soldner concluiu que a deflexão total entre as duas assíntotas da hipérbole, uma vinda do infinito até a superfície do corpo e outra indo da superfície do corpo até o infinito, seria de 0,84" (SOLDNER, 18046; SOARES, 20097). Nesse cálculo, bastante preciso para a época ${ }^{8}$, foram utilizados os valores de então para a velocidade da luz, a massa e o raio do Sol. Mas Soldner nem tentou confirmar empiricamente essa predição, pois sabia que ela estava além da capacidade da instrumentação então disponível.

Apesar de Soldner ter publicado seu resultado numa revista bastante lida, e de ter sido lembrado por suas inúmeras contribuições em outros temas científicos, estranhamente este artigo permaneceu praticamente ignorado, tanto que só em 1978 o beneditino húngaro e filósofo da ciência, Stanley L. Jaki (1924-2009) publicou no final de um artigo (JAKI, 1978) ${ }^{9}$ a tradução para o inglês intitulada On the deviation of a light ray from its motion along a straight line through the attraction of a celestial body which it passes close by (JAKI, 1978, pp. 939-948) ${ }^{10}$. A obscuridade em que Soldner permaneceu pode ser atribuída ao fato de que ele era de origem simples, foi autodidata e não tinha recebido educação formal. Mas ele era muito talentoso, tanto que no Observatório de Berlim foi assistente de Johann Elert von Bode (1747-1826), astrônomo real da Prússia amplamente conhecido por aquela lei planetária que leva o seu nome. Se Soldner teve admiradores, também teve detratores que o invejavam. O valor em si da deflexão calculado por ele tem importância, mas Jaki sublinhou a profundidade da Filosofia Natural de Soldner, que já o fizera aceitar a possibilidade da variação da velocidade da luz ${ }^{11}$, enquanto Pierre-Simon Laplace (17491827), ao propor em 1796, depois portanto das estrelas obscuras de Michell, contudo de forma independente, as estrelas invisíveis (atuais buracos negros) em Exposition du Système du Monde, considerava constante a velocidade da luz (JAKI, 1978, pp. 935-937) ${ }^{12}$. Reconhecendo nessa constância uma contradição com o comportamento da luz na estrela invisível, Laplace teria reti-

${ }^{6}$ SOLDNER, Johann Georg von. Über die Ablenkung eines Lichtstrals von seiner geradlinigen Bewegung durch die Attraktion eines Weltkörpers, an welchem er nahe vorbeigeht. Berliner Astronomisches Jahrbuch, 161172, 1804. O artigo foi publicado em 1804, mas escrito em 1801.

7 SOARES, Domingos S. L. Newtonian gravitational deflection of light revisited. arXiv: physics/0508030v4 [physics.gen-ph] 17 Apr 2009. Disponível em <http://xxx.if.usp.br/abs/physics/0508030>. Acesso em 15/12/2018.

${ }^{8}$ Em 1911, 110 anos depois, Einstein obteria 0,83".

9 JAKI, Stanley L. Johann Georg von Soldner and the Gravitational Bending of Light, with an English Translation of His Essay on It Published in 1801, Foundations of Physics, v. 8, n. 11-12, 927- 950, 1978.

${ }^{10}$ JAKI, Stanley L. Ibid., 1978, pp. 939-948.

${ }_{11}$ A velocidade da luz no vácuo é uma constante física universal, quando medida por observadores num sistema de referência inercial (ver adiante). Segundo a Relatividade Restrita essa velocidade independe do movimento relativo do observador em relação à fonte de luz. Mas a variação da velocidade da luz será um conceito-chave na transição da Relatividade Restrita para a Relatividade Geral.

12 JAKI, Stanley L. Ibid., 1978, pp. 935-937. 
rado sua proposta a partir da terceira edição de sua obra (1808). Segundo o físico teórico americano e Prêmio Nobel de Física de 2017 Kip Thorne (1940-), a retirada teria sido motivada pela crescente aceitação da teoria ondulatória da luz (THORNE, 1994, p. 123) ${ }^{13}$.

De fato, a publicação em 1801 dos experimentos do físico e polímata britânico Thomas Young (1773-1829) sobre a interferência da luz, ofuscou temporariamente a teoria corpuscular da luz. Se a luz fosse apenas uma onda se propagando num éter imponderável - noção que se tornaria vigente -, não haveria lugar para a deflexão da luz. Isso ajudou a sepultar a ideia das estrelas obscuras e da influência da gravidade na luz, sendo que esta ressurgiria só em 1915 com Einstein.

\section{Da Relatividade Restrita à Relatividade Geral}

Dos cinco trabalhos que Albert Einstein (1879-1955) publicou no Annus Mirabilis da Física, $1905^{14}$, na revista Annalen der Physik, um era sobre a eletrodinâmica dos corpos em movimento. Esse artigo lançou a primeira parte da Relatividade que hoje chamamos Relatividade Restrita. Nela Einstein postulou a constância da velocidade da luz no vácuo, sua independência em relação ao movimento da fonte ou do observador e que essa teoria descrevesse, da mesma forma, os fenômenos físicos mesmo que fossem observados por diferentes observadores em referenciais inerciais ${ }^{15}$. Daí ele deduziu os resultados surpreendentes da dilatação do tempo e contração do espaço (a relatividade do tempo e do espaço em relação ao estado de movimento do observador), efeitos esses que se tornam mais notáveis a altas velocidades, aquelas que se aproximam da velocidade da luz. Utilizando a invariância da velocidade da luz, Einstein acoplou o espaço e o tempo, ambos relativos, no novo conceito de um espaço-tempo absoluto (EINSTEIN, 1905) ${ }^{16}$. Mas quem amalgamou geometricamente o espaço tridimensional e o tempo unidimensional num único contínuo quadridimensional absoluto, independente do movimento do observador, foi o matemático Hermann Minkowski (1864-1909). Minkowski tinha sido professor de Einstein em Zurique. Ele, como vários outros professores, não via com simpatia o modo de ser desatento e irreverente desse aluno, tanto que o chamou de "cão vadio" (THORNE, 1994, p. 61 $)^{17}$. Mas, anos depois, Minkowki tomou conhecimento do artigo de 1905 de Einstein sobre Relatividade Restrita, que o deixou deveras admirado. Em 1907, quando lecionava em Göttingen, Minkowski concebeu o chamado espaço-tempo de Minkowski, um contínuo quadrimensional

13 THORNE, Kip S. Black Holes and Time Warps. Einstein's Outrageous Legacy. New York: W. W. Norton \& Company, 1994, p. 123.

${ }^{14}$ Nesse ano Einstein era funcionário do Escritório de Patentes em Berna, Suíça.

15 Referenciais inerciais são sistemas de referência atados a observadores que se encontram em repouso ou em movimento retilíneo e uniforme.

16 EINSTEIN, Albert. Zur Elektrodynamik bewegter Körper. Annalen der Physik, v. 322, n. 10, 891-921, 1905.

17 THORNE, Kip S. Ibid., 1994, p. 61. 
plano, portanto sem curvatura. Quando soube, Einstein viu com desdém o trabalho de seu exmestre e considerou que a Matemática por ele empregada apenas obscurecia a Física.

Em 1907 Einstein foi convidado a escrever um artigo de revisão sobre a Relatividade Restrita, que saiu publicado em $1908^{18}$. A essas alturas Einstein já tinha detectado um ponto de insatisfação em sua Relatividade Restrita. A seu ver, uma boa teoria física deveria se aplicar também a referenciais não inerciais, aqueles que estão submetidos a aceleração (situações em que a velocidade pode variar em módulo, aumentando ou diminuindo, como também na direção). Einstein se sentiu, então, compelido a generalizar a Relatividade Restrita. No fundo, esta era a tarefa de ajustar a Teoria da Gravitação de Newton à nova concepção de espaço e tempo da Relatividade Restrita.

Enquanto pensava nessa questão, fazendo um Gedanken-Experiment (experimento mental realizado não em laboratório, mas "na cabeça"), Einstein teve o que ele considerou a ideia mais feliz de sua vida: a de que para um observador numa cabine em queda livre num campo gravitacional, ignorando-se o atrito do ar, tudo se passava como se estivesse num sistema inercial. De fato, numa cabine sem janelas o observador experimentador não notaria a queda, de modo que, estar em queda livre era uma forma de suprimir a gravidade. Assim, num sistema em queda livre os princípios da Relatividade Restrita continuavam válidos, e esse foi o ponto de partida para a generalização da Relatividade Restrita.

Um observador experimentador também não notaria diferença se, em vez de estar sob a ação da gravidade, por exemplo, na superfície da Terra, estivesse numa cabine fechada no espaço vazio, propelida por um foguete capaz de produzir uma aceleração equivalente à da gravidade na superfície da Terra. Assim Einstein enunciou o Princípio da Equivalência, segundo o qual a massa inercial se tornava equivalente à massa gravitacional (essas massas, segundo Newton, constituíam conceitos distintos) e um referencial acelerado uniformemente seria equivalente a um campo gravitacional homogêneo ${ }^{19}$.

No artigo de revisão publicado em 1908, Einstein acrescentou uma $5^{\text {a }}$ parte sobre o Princípio da Relatividade e a Gravitação. Nela antecipou algumas ideias da Relatividade Geral fazendo a apresentação do Princípio da Equivalência e anunciando que a Gravitação requeria que a Relatividade Restrita incluísse o movimento acelerado e, para isso, deveria receber uma extensão baseada nesse Princípio. Na construção da teoria da Relatividade Geral esse foi apenas

${ }^{18}$ EINSTEIN, Albert. Über das Relativitätsprinzip und die aus demselben gezogenen Folgerungen, Jabrbuch der Radioaktivität und Electronik, v. 4, 411-462, 1908.

${ }^{19}$ Homogêneo porque, no tamanho reduzido de uma cabine não se poderia emular, p. ex., a convergência do campo gravitacional para o centro da Terra. 
o passo inicial de um penoso empreendimento intelectual. A longa e difícil formalização da Relatividade Geral só se completaria 7 anos depois, em 1915, após marchas, titubeios e contramarchas.

Emulando a gravidade numa cabine acelerada uniformemente no espaço livre, Einstein identificou os seguintes efeitos da Relatividade Restrita que, pelo Princípio de Equivalência, ele atribuiu à gravidade: a) a marcha do relógio no fundo da cabine era mais lenta do que a do relógio no topo da cabine ${ }^{20}$; pelo Princípio de Equivalência, a marcha mais lenta ocorria onde a gravidade era mais intensa e vice-versa ${ }^{21}$; b) para um observador num compartimento acelerado, um raio luminoso horizontal sofreria queda como os demais objetos (numa cabine inercial, a trajetória da luz seria retilínea). Segundo o Princípio de Equivalência haveria deflexão gravitacional da luz; c) não só a direção da luz muda, como também sua celeridade, de modo que há variação gravitacional da velocidade da luz. A celeridade da luz é menor onde a gravidade é mais intensa. Isso não contradiz o postulado inicial da invariância da velocidade da luz porque a velocidade depende da medição do espaço e do tempo, portanto da régua e do relógio utilizado. Assim, não num sistema inercial, mas num sistema de referência em repouso em relação a uma fonte de gravidade, a velocidade da luz pode variar sob o efeito da gravidade, o que deverá ser entendido adiante como deformação ou curvatura do espaço-tempo que afeta a régua e o relógio utilizados para medir a velocidade da luz.

Considerando o efeito (a) e os átomos do Sol que emitem radiação numa frequência fixa como relógios naturais, Einstein predisse o deslocamento para o vermelho (comprimentos de onda mais longos) de linhas espectrais da luz solar. Tendo em vista o efeito (b) predisse a deflexão gravitacional da luz, mas ainda de forma incompleta. O efeito (c) insinuava a ideia central da Relatividade Geral de que a gravidade encurvava a trajetória da luz, ou melhor, que a gravidade era o encurvamento do espaço-tempo. A introdução da noção de curvatura do espaçotempo foi uma inflexão crucial na construção da Relatividade Geral. A geometria clássica do espaço era a de Euclides, a do espaço plano. Mas, desde 1830 já tinham sido inventadas as geometrias curvas ou não euclidianas. A questão agora era introduzir a curvatura no espaço-tempo, lembrando que o espaço tridimensional ordinário podia ser matematicamente extraído do espaço-tempo quadridimensional, impondo-se a anulação de qualquer variação temporal (tecnicamente, $d t=0$ ), ou seja, "congelando-se" o tempo.

\footnotetext{
20 Por um observador externo e estacionário, o relógio do alto da cabine acelerada passa primeiro a uma velocidade menor que o relógio do fundo da cabine que passa depois. Segundo a Relatividade Restrita, o relógio do fundo, por se deslocar a maior velocidade, marcha mais devagar, ou seja, sofre maior dilatação do tempo.

${ }^{21}$ Uma sutil distinção deve ser notada. Na Relatividade Restrita, como o movimento entre observadores inerciais é relativo, ambos os observadores vêem, da mesma forma, a dilatação do tempo do outro. Na Relatividade Geral a dilatação do tempo não tem essa simetria e ocorre quando o observador está num campo gravitacional intenso e a dilatação é tanto maior quanto mais intenso é esse campo.
} 
Segundo JAKI (1978, p. 928)22, no artigo de revisão Einstein teria dito in a tone of unmistakable originality that gravitation must have an influence on the path of light and gave a formula for its deflection per centimeter [of the optical path]. Jaki concedeu, no entanto, que Einstein foi original ao postular a deflexão da luz a partir do Princípio da Equivalência, embora a equação que dava a deflexão da luz por centímetro do trajeto da luz estivesse errada. Baseava-se apenas no Princípio da Equivalência, sem levar em conta a curvatura do espaço-tempo. A essas alturas Einstein também não tinha se dado conta ainda de que a deflexão poderia ser testada observacionalmente durante um eclipse total do Sol (NORTH, 2007) $)^{23}$.

Em 1911, quando lecionava em Praga, insatisfeito com as ideias apresentadas no artigo de 1908, Einstein retomou a questão da influência da gravidade na propagação da luz e escreveu um novo artigo em forma preliminar e simplificada (EINSTEIN, 1911) ${ }^{24}$. Considerando o Princípio da Equivalência, a massa-energia equivalente de um fóton e o Princípio de Huygens (que prescreve a formação e propagação de frentes de onda da luz), demonstrou que a deflexão da luz era devida ao potencial gravitacional, obtendo para um raio rasante ao Sol uma deflexão de 0,83 ”. Mas esse ainda era um resultado conceitualmente falho. Numericamente era o mesmo que se obtinha a partir da Gravitação de Newton, supondo que a luz era constituída de partículas dotadas de massa. Na ocasião, nem Einstein, nem os leitores deste artigo de 1911 se deram conta de que, mais de um século antes, Soldner já tinha obtido quase o mesmo valor (JAKI, 1978, p. 928) 25 . Porém, o cálculo de Soldner era clássico, enquanto o de Einstein pretendia ser relativístico e ainda necessitava de acertos. Essa predição equivocada da deflexão da luz foi chamada "predição de Praga", pois ali Einstein estava trabalhando. Desta vez ele não só anunciou o valor da deflexão da luz, ainda que incorreto, mas urgiu os astrônomos para que testassem sua predição num eclipse total do Sol. Mas a reação a esta conclamação foi quase um completo silêncio.

\section{Verificação da deflexão gravitacional da luz}

\section{Tentativas com valor equivocado}

O Imperial Observatório do Rio de Janeiro, atual Observatório Nacional, tinha a tradição de organizar expedições no país para a observação de eclipses solares. Essa tarefa incluía também a prestação de assistência a expedições estrangeiras. Segundo BARBOZA (2007) ${ }^{26}$ e

22 JAKI, Stanley L. Ibid, 1978, p. 928.

${ }_{23}$ NORTON, John D. Einstein's Pathway to General Relativity. In Einstein for Everyone. Pittsburgh, PA: Nullarbor Press, 2007, Chapter 26. Disponível em <https://www.pitt.edu/ jdnorton/teaching/HPS_ 0410/chapters/general_relativity_pathway/index.html >. Acesso em 5/1/2019.

24 EINSTEIN, Albert. Über den Einfluss der Schwercraft auf die Ausbreitung des Lichtes, Annalen der Physik, v. 35, n. 4, 898-908, 1911.

25 JAKI, Stanley L. Ibid., 1978, p. 928.

26 BARBOZA, Christina Helena. A observação de eclipses totais do Sol no Brasil, Com Ciência, Revista Eletrônica de Jornalismo Científico, v. 90, 1-6, 2007. 
BARBOZA (2010) 27, de 1858 até 1893 foram organizadas expedições para três eclipses e em todos eles o objetivo primordial dos astrônomos brasileiros era o estudo de fenômenos da atmosfera solar (Física Solar) e os efeitos do eclipse na ionosfera e magnetosfera terrestre. O próximo eclipse total do Sol no Brasil foi o de 10/10/1912. Este merece destaque porque, pela primeira vez, uma real tentativa de verificar a deflexão da luz (embora com valor equivocado) chegou a ser efetivada, mas não deu certo por causa do mau tempo. Isso foi anterior à tentativa que veremos adiante, de Freundlich na Rússia, propalada como pioneira por muitos autores. Os postos de observação no Brasil para esse eclipse de 1912 foram Passa Quatro, Alfenas e Cristina em MG e Cruzeiro em SP (OLIVEIRA, 2010) ${ }^{28}$. A expedição argentina, chefiada pelo então diretor do Observatório de Cordoba, Charles Dillon Perrine (1867-1951) se instalou em Cristina e era a que, além de outros objetivos científicos, pretendia confirmar a deflexão gravitacional da luz pelo Sol. Para isso a equipe trouxe dois telescópios gêmeos com objetiva de 7,5 cm de diâmetro e foco de 3,35 m (PAOLANTONIO, 2019)29. A expedição do Observatório Nacional se instalou em Passa Quatro, assim como a expedição do Observatório de Greenwich, liderada pelo astrônomo Arthur Stanley Eddington (1882-1944), de quem muito falaremos adiante. Todas as equipes fracassaram nas observações, pois choveu torrencialmente em todos os postos observacionais.

Conforme veremos, após a observação do eclipse total do Sol de 1919, seria anunciada bombasticamente a confirmação da deflexão da luz predita por Einstein, episódio no qual Eddington foi personagem central. Mas é interessante assinalar que 7 anos antes, no eclipse de Passa Quatro, o objetivo da observação de Eddington era exclusivamente voltado à Física Solar: estrutura da coroa solar e espectroscopia da cromosfera e coroa (EDDINGTON, 191330; EDDINGTON and DAVIDSON, 1913¹). Portanto, no eclipse de 1912 a observação da deflexão da luz estava completamente fora da pauta de Eddington, de modo que, quando ele observou o eclipse de 1919, o seu interesse por esse assunto era relativamente recente.

${ }^{27}$ BARBOZA, Christina Helena. Ciência e natureza nas expedições astronômicas para o Brasil (1850-1920), Bol. Mus. Para. Emílio Goeldi. Cienc. Hum., Belém, v. 5, n. 2, 273-294, 2010.

28 OLIVEIRA, Raquel dos Santos. O eclipse de 1912 e a correspondência entre os astrônomos Morize e Perrine, XIV Encontro Regional da ANPUH-Rio, "Memória e Patrimônio", UNIRIO, Rio de Janeiro, 1923/07/2010, 2010. Disponível em http://www.encontro2010.rj.anpuh.org/resources/anais/8/1277123754_ARQUIVO_O_eclipse_de_1912_e_a_correspondencia_entre_os_astronomos_Morize_e_Perrine.pdf. Acesso em 20/2/19.

29 PAOLANTONIO, Santiago. Exposición - Argentina y la verificación de la Teoría de la Relatividad. Historia de la Astronomía. Historia de la astronomía Argentina y Latinoamericana. Disponível em https:/ / historiadelaastronomia.wordpress.com/documentos/exposicioneclipse/ 2019. Acesso em 23/2/19.

${ }^{30}$ EDDINGTON, A. S. The Greenwich Eclipse Expedition to Brazil, The Observatory, v. 36, n. 457, 62-65, 1913.

31 EDDingTON, A. S. and DAVIDSON, C. Total Eclipse of the Sun, 1912 October 10. Report on an Expedition to Passa Quatro, Minas Geraes, Brazil, Monthly Notices of the Royal Astronomical Society, v. 73, n. 5, 386-390, 1913 
Mas, como Perrine, na Argentina, teria sido alertado para a pretensão de Einstein de confirmar a deflexão da luz num eclipse solar? Isso fica esclarecido no artigo de PAOLANTONIO e MINNITI (2007) ${ }^{32}$. Perrine era um astrônomo americano que tinha trabalhado de 1893 a 1909 no Observatório de Lick. Aí ele conheceu William Wallace Campbell (1862-1938) que foi diretor daquele observatório da Universidade da Califórnia. Campbell era respeitado como exímio espectroscopista estelar da área de velocidades radiais ${ }^{33}$, mas também tinha experiência na observação de eclipses solares (BARKER, 1922) 34. Ele já tinha observado eclipses na Índia em 1898, no estado americano da Geórgia em 1900, na Espanha em 1905, no Pacífico Sul em 1908. Pelo Observatório de Lick Perrine tinha participado de 4 expedições a eclipses solares (1889 na Califórnia, 1900 no estado da Geórgia, 1901 em Sumatra e 1905 na Espanha). De 1909 a 1936 assumiu a direção do Observatorio Nacional Argentino, em Córdoba.

Para colaborar com Einstein, um jovem astrônomo alemão, Erwin-Finlay Freundlich (1885-1964), assistente do Observatório de Berlim, cogitou inicialmente em examinar fotografias de eclipses passados. Após Perrine ter participado em Paris, em outubro de 1911, da reunião da Comissão da Carte du Cieß5, no caminho para o Observatório de Pulkovo em São Petersburgo, Perrine fez uma escala de poucas horas em Berlim, quando contatou Freundlich. Este consultou Perrine sobre a possibilidade de utilizar as fotografias obtidas por ele nas expedições para eclipses de que participara pelo Observatório de Lick, procurando um planeta entre o Sol e Mercúrio ${ }^{36}$. A consulta fazia sentido, pois Perrine, juntamente com Campbell, tinha utilizado no estado americano da Geórgia a câmara de 40 pés do Observatório de Lick no eclipse de 29/5/1900 (PEARSON and ORCHISTON, 2008, 30-31) ${ }^{37}$, quando o campo estelar fotografado era excelente para a verificação da deflexão da luz, quase o mesmo campo do futuro eclipse de 1919 (EARMAN and GLYMOUR, 1980a, 61) ${ }^{38}$. Mas a resposta imediata de Perrine a Freundlich foi negativa, aduzindo que nas imagens obtidas o Sol não se encontrava no centro das placas. Mesmo assim, Freundlich solicitou as fotografias a Campbell e as analisou, mas não obteve resultados satisfatórios.

32 PAULANTONIO, Santiago y MINNITI, Edgardo R.. Intentos argentinos para probar la Teoría de la Relatividad, Presentación Oral, Reunión Anual, Asociación Argentina de Astronomía, Malargüe, Mendoza, 15 al 19 de septiembre de 2007, Boletín de la Asociación Argentina de Astronomía, v. 50, 359-362, 2007.

33 A velocidade radial é a componente da velocidade de um astro na direção da linha de visada da observação.

${ }^{34}$ BARKER, Geoff. Einstein's Theory of Relativity Proven in Australia, 1922, Inside the Collection. Disponível em https://maas.museum/inside-the-collection/2012/08/22/einsteins-theory-of-relativity-proven-inaustralia-1922/ Acesso em 15/1/19.

35 Carte du Ciel era o nome de um projeto de colaboração internacional proposto em 1887 pelo diretor do Observatório de Paris, que objetivava utilizar o então moderno método fotográfico, para mapear e catalogar milhões de estrelas de todo o céu com brilho superior à magnitude 11-12.

${ }^{36}$ Esse hipotético planeta denominado Vulcano foi procurado com o intuito de solucionar o problema da anomalia do deslocamento do periélio de Mercúrio sem sair da teoria gravitacional de Newton. Mas, como veremos, esse problema viria a ser solucionado pela Relatividade Geral de Einstein.

${ }^{37}$ PEARSON, John C. and ORCHISTON, Wayne. The 40-foot Solar Eclipse Camera of the Lick Observatory, Journal of Astronomical History and Heritage, v. 11, n. 1, 25-37, 2008, pp. 30-31.

38 EARMAN, J. and GLYMOUR, C. Relativity and eclipses: The British eclipse expeditions of 1919 and their predecessors, Historical Studies in the Physical Sciences, v. 11, n. 1, 49-85, 1980a, p. 61. 
No início de 1912, através de uma carta, Freundlich solicitou a PERRINE (1923) ${ }^{39}$ que fizesse observações para detectar a deflexão da luz no próximo eclipse solar. Perrine aceitou o pedido e a primeira oportunidade que surgiu foi o eclipse de 1912 no Brasil. Campbell também quis observar esse eclipse mas, não podendo enviar uma expedição pelo Observatório de Lick, emprestou as objetivas que tinham sido usadas na busca do planeta transmercurial. Em Córdoba foram especialmente desenhados e confeccionados vários instrumentos. A expedição liderada por Perrine contou com 3 assistentes. As objetivas emprestadas por Campbell seriam utilizadas para verificar a deflexão da luz. Outros instrumentos fariam observações em Física Solar. Mas, como já disse, as chuvas frustraram os planos. PAOLANTONIO e MINNITI (2007, p. 361) 40 assim concluíram: Esta fue la primera tentativa argentina de probar la nueva Teoría de la Relatividad por medio de observaciones astronómicas, anticipándose siete años a la exitosa expedición inglesa de 1919, lo cual destaca su importancia. Num artigo de 1923 Perrine escreveu: I am not aware that any other expedition attempted such observations at the 1912 eclipse, or previously. It appears, therefore, that the Córdoba Observatory made the first definite attempt to secure observations at an eclipse [that of 1912] for the relativity problem and that was done at the instigation of Dr. Freundlich (PERRINE, 1923, p. 284) ${ }^{41}$. Ao Brasil coube sediar essa tentativa pioneira.

Ainda no interesse de testar a previsão da deflexão da luz, em $1913^{42}$ Einstein consultou o astrônomo solar norte-americano, George E. Hale (1868-1938), se o teste poderia ser realizado com o Sol, mas fora de um eclipse. Em sua resposta negativa Hale explicou que o brilho do céu nas proximidades do Sol não eclipsado era muito intenso (NORTH, 2007) ${ }^{43}$, de sorte que as estrelas eram obliteradas.

Em março de $1914^{44}$ Freundlich chamou a atenção dos colegas para a oportunidade que se ofereceria no eclipse solar de 21 de agosto daquele ano na Crimeia, para a confirmação da deflexão, mas isso não suscitou interesse entre os colegas mais próximos. Freundlich não obteve apoio financeiro de seu superior Hermann Struve (1854-1920), mas teve o apoio de Einstein para obter fundos privados, já que não havia possibilidade de fundos oficiais. Também teve a ideia de recontatar Campbell para convidá-lo para observar o eclipse de 1914 na Rússia, no que foi atendido.

${ }^{39}$ PERRINE, C. D. Contribution to the history of attempts to test the theory of relativity by means of astronomical observations, Astronomische Nacbrichten, v. 219, 281-284, 1923.

40 PAULANTONIO, Santiago y MINNITI, Edgardo R. Ibid., 2007, p. 361.

41 PERRINE, C. D. Ibid., 1923, p. 284.

42 Entre 1912 e 1913 Einstein voltou a lecionar em Zurique.

${ }^{43}$ NORTON, John D. Ibid., 2007.

${ }^{44}$ Nesse ano, a convite do físico teórico alemão Max Planck (1858-1947), pai da Física Quântica e Prêmio Nobel de Física de 1918, Einstein foi morar em Berlim onde permaneceu até 1933. Nesse ano, por estar até mesmo ameaçado de morte, decidiu deixar definitivamente a Alemanha e mudou-se para os Estados Unidos. Einstein era alemão de nascimento, mas tendo renunciado a cidadania alemã em 1896, obteve a cidadania suiça em 1901 que manteve por toda a vida e em 1940 ganhou também a cidadania americana. 
Apesar de ter fracassado no eclipse de 1912 no Brasil, Perrine não desistiu e aguardou a seguinte oportunidade que foi o eclipse de 1914. Tendo obtido peças emprestadas por Perrine, Freundlich montou 4 telescópios e conseguiu organizar uma expedição para Feodósia, na Crimeia, às margens do Mar Negro. Essa expedição deveria se encontrar com a da Argentina chefiada por Perrine para juntos observarem o eclipse. Perrine seguiu para lá com apenas um assistente. Apesar das dificuldades financeiras, levou os mesmos equipamentos levados para Cristina. Mas, então, eclodiu a I Guerra Mundial. Por ser cidadão alemão e tendo a Alemanha recémdeclarado guerra à Rússia, Freundlich foi considerado potencial espião pelos russos que o detiveram com os seus assistentes como prisioneiros de guerra, e confiscaram seus instrumentos. Freundlich não pôde fazer a observação. A equipe argentina também não pôde fazer as observações porque, devido à Guerra, sua instrumentação não chegou em tempo hábil (EARMAN and GLYMOUR, 1980a, p. 62 ${ }^{45}$.

Campbell, por sua vez, acompanhado do astrônomo Heber D. Curtis (1872-1942) ${ }^{46}$, também do Observatório de Lick, se deslocou para as proximidades de Kiev. Sendo da América neutra, não foi impedido de fazer a observação. Mas a observação não pôde ser feita por causa do mau tempo (CAMPBELL and CURTIS, 1914) ${ }^{47}$.

Consta que das 27 expedições para esse eclipse, apenas 7 puderam assestar os instrumentos para as observações mas, então, o óbice foram as nuvens que cobriram parcialmente o Sol durante o fenômeno. Entre uma nuvem e outra poucas imagens foram obtidas, mas de pouca utilidade. Todavia, essas foram as primeiras imagens obtidas com o objetivo de verificar a predição de Einstein.

O fracasso total e completo das tentativas de observação do eclipse de 1914 na Rússia, assim como o fraco interesse dos astrônomos aos apelos de Einstein, foram providenciais para ele, pois o cálculo do desvio da luz continha um erro. Sua teoria ainda não era a teoria completa da Relatividade Geral, porquanto ainda não incluía o encurvamento do espaço-tempo nas proximidades do Sol. Se as medições da deflexão da luz tivessem sido feitas com sucesso na então Rússia Imperial, os resultados observacionais teriam “derrubado” Einstein.

45 EARMAN, J. and GLYMOUR, C. Ibid., 1980a, p. 62.

46 Heber Curtis e seu colega, Harlow Shapley (1885-1972) foram os protagonistas do Grande Debate público realizado em 1920 em Washington, para debater a natureza das galáxias espirais e o tamanho do Universo. Shappley achava que essas galáxias eram objetos relativamente pequenos, que se achavam na periferia da nossa própria Galáxia, enquanto Curtis defendia que se tratava de galáxias independentes da nossa, que portanto eram gigantescas e se encontravam muito longe, o que levava a crer que o Universo era muito maior do que se pensava. Curtis defendeu a tese que se mostraria correta.

47 CAMPBELL. W. W. and CURTIS, Heber, D. The Lick Observatory-Crocker Eclipse Expedition to Brovarý, Russia, Publications of the Astronomical Society of the Pacific, v. 26, n. 155, 224-237, 1914. 
Perrine ainda organizou uma nova expedição para o eclipse de 3/2/1916 em Tucacas, na Venezuela. Por causa da crise provocada pela I Guerra, poucas eram as expedições e a equipe argentina contou com apenas um astrônomo auxiliar de Perrine, que nem pôde levar os melhores equipamentos (PAULANTONIO y MINNITTI, 2018) ${ }^{48}$. A Relatividade nem chegou a fazer parte do programa daquele eclipse (PERRINE, 1923, p. 284) ${ }^{49}$, mas já era conhecido o valor correto da deflexão da luz. Depois de ter chovido copiosamente pela manhã, durante o eclipse a chuva parou, mas tênues nuvens atrapalharam a observação da totalidade. Foram obtidas imagens, mas nenhuma que servisse para a verificação da deflexão da luz.

Perrine ainda trocou correspondência com o diretor do Observatório Nacional do Rio de Janeiro, Henrique C. Morize (1860-1930), solicitando informações sobre a melhor localidade para observar o eclipse de 29/5/1919, eclipse esse que tinha a vantagem de uma totalidade com duração máxima de quase 7 minutos, realmente longa. Morize produziu uma circular técnica que distribuiu internacionalmente aos interessados (VIDEIRA, 2005) s0 $^{50}$ tendo feito uma visita preparatória a Sobral em março de 1919 (CRISPINO e LIMA, 2018) ${ }^{51}$ para designar as autoridades locais que prestariam assistência às expedições. Na circular, o local sugerido foi Sobral por ser o mais adequado e foram fornecidas abundantes informações sobre as condições meteorológicas, forma de acesso etc. (DYSON, EDDINGTON and DAVIDSON, 1920, p. 295) 52. Apesar de Perrine ter feito planos de uma expedição para esse eclipse, os grandes gastos feitos nas três expedições anteriores sem obter resultados, e o imperativo de priorizar programas da própria instituição, forçaram o cancelamento da expedição que, dessa vez, teria encontrado condições meteorológicas favoráveis para a obtenção de imagens para verificar a predição de Einstein.

O valor correto da deflexão só foi conhecido em 1915. Até 1912 Einstein tinha usado em seus raciocínios apenas métodos algébricos em que os tempos e as velocidades apareciam como variáveis. Mas em 1911, como vimos, ele tinha constatado que a velocidade da luz variava localmente de acordo com a intensidade da gravidade. Segundo o Princípio de Fermat, enunciado em 1662 pelo matemático francês Pierre de Fermat (1606-1665), o caminho de um raio de luz entre dois pontos é aquele que pode ser percorrido no menor tempo. O trajeto mais curto entre dois pontos do espaço é tecnicamente chamado geodésica. Se o espaço é euclidiano (ou plano), por definição ele obedece aos postulados da Geometria de Euclides, p. ex., que a soma

48 PAOLANTONIO, S. y MINNITI MORGAN, E. R. Attempts to prove Einstein's Theory of Relativity, Trad. para o inglês por A. D. Cuestas, E. E. Scorians y M. E. Valotta, de "Intentos para probar la Teoría de la Relatividad de Einstein”, Cap. 20, Córdoba Estelar, Historia del Observatorio Nacional Argentino, 2018. ${ }^{49}$ PERRINE, C. D. Ibid., 1923, p. 284.

50 VIDEIRA, Antonio Augusto Passos. Einstein e o Eclipse de 1919, Física na Escola, v. 6, n. 1, 83-87, 2005. ${ }^{51}$ CRISPINO, Luís Carlos Bassalo e LIMA, Marcelo Costa. Expedição norte-americana e iconografia inédita de Sobral em 1919, Revista Brasileira de Ensino de Física, v. 40, n. 1, e1601-1 a e1601-8, 2018. DOI: $<$ http://dx.doi.org/10.1590/1806-9126-RBEF-2017-0092>. Acesso em 28/2/19.

52 DYSON, F. W., EDDINGTON, A. S. and DAVIDSON, C. A Determination of the Deflection of Light by the Sun's Gravitational Field, from Observations made at the Total Eclipse of May 29, 1919, Philosophical Transactions of the Royal Society of London, Series A, v. 220, 291-333, 1920, p. 295. Este é o artigo mais detalhado sobre o projeto das expedições britânicas para a confirmação da deflexão gravitacional da luz no eclipse de 1919. 
dos ângulos de um triângulo plano é sempre $180^{\circ}$; o perímetro de um disco de raio $r$ é $2 \pi r$ e a geodésica é um segmento de reta. Mas se o espaço for curvo ou não-euclidiano (algo sugerido pela variação da velocidade da luz em função da gravidade), a geodésica é curva.

Ora, através do Princípio da Equivalência Einstein tinha concluído que a aceleração linear uniforme produzia um campo gravitacional homogêneo. Agora, com outro Gedanken-Experiment ele descobrirá que um outro tipo de aceleração, a rotação, produzia uma geometria nãoeuclidiana. Num disco com um certo raio, mas que gira, um observador externo não notará nenhuma alteração no tamanho do raio do disco, pois na rotação o movimento é perpendicular ao raio. Mas notará que o perímetro do disco já não é mais $2 \pi$, mas um número maior que $2 \pi$ multiplicado pelo raio. O raio do disco, usado agora como padrão de medida na borda do disco em rotação, sofre contração (efeito da Relatividade Restrita), assim aquele algo maior que $2 \pi$ é a compensação necessária. Em outras palavras, a rotação (e a consequente aceleração centrífuga da mecânica newtoniana que agora emula a gravidade) produz uma geometria não-euclidiana. Essa geometria pode ter curvatura positiva (fechada) ou negativa (aberta), mas a rotação produz curvatura negativa. Se o disco em rotação atuasse como uma plataforma giratória para a construção nela de um triângulo com vértices nos pontos A, B e C, para um observador externo os lados desse triângulo não seriam linhas retas, mas curvadas convexamente para o interior do triângulo, de modo que a soma dos ângulos internos seria $<180^{\circ}$, propriedade condizente com a curvatura negativa. Os lados curvos seriam as trajetórias curvas da luz, portanto as geodésicas curvas.

A deflexão da luz seria então porque o espaço-tempo se tornava curvo pela presença da matéria.

Era a curvatura do espaço-tempo que regia a trajetória da luz e de todos os corpos, não mais a força proposta por Newton. Agora a teoria de Einstein deveria incorporar a ideia de que a presença da matéria encurva o espaço-tempo, explanação essa que requeria um formalismo matemático mais poderoso.

Aconselhado em 1912 por seu ex-colega e amigo dos tempos de Zurique, o matemático Marcel Grossmann (1878-1936), Einstein, depois de relutar por muitos anos aceitou ser introduzido ao Cálculo Tensorial ${ }^{53}$, ferramenta matemática indispensável para o desenvolvimento da

53 Como o nome diz, o Cálculo Tensorial lida com entidades matemáticas chamadas tensores. O tensor pode ser entendido como uma forma generalizada para representar grandezas físicas de diferentes ordens: escalares (ordem $=0$, p. ex., temperatura), vetores (ordem $=1$, p. ex., velocidade cujas componentes assumem 3 valores distintos correspondentes às 3 coordenadas do espaço tridimensional) ou matrizes (ordem $=2,3,4, \ldots)$. Tomando como exemplo um objeto sólido deformável pela aplicação de uma força externa, podemos imaginariamente seccioná-lo segundo um plano. Para um elemento de área infinitesimal desse plano, a força que ali atua dividida pela área é chamada estresse (ou tensão) que pode ser normal ou tan- 
Teoria da Relatividade Geral. No fundo Einstein acabou reconhecendo que o espaço-tempo plano de Minkowski, do qual havia desdenhado, era o que precisava ser deformado ou encurvado para descrever a presença da matéria e energia, dando lugar ao surgimento da gravidade. Da colaboração entre Einstein e Grossmann resultou em 1913 um primeiro artigo sobre a Relatividade Geral (EINSTEIN and GROSSMANN, 1913)54, com o raciocínio físico no qual a teoria era baseada (Parte I) escrito por Einstein e a matemática tensorial utilizada (Parte II), por Grossmann. Einstein chegou a apresentar dez equações não-lineares acopladas que ele considerou corretas. Elas eram complicadas e nem sequer tinham sido interpretadas geometricamente. Com a publicação desse trabalho, feita com certo alarde, Einstein achou que a maior parte da sua teoria estava pronta. Apenas faltariam detalhes a serem esclarecidos. Mas esse sentimento ilusório durou pouco. Einstein descobriu um erro fatal, pois suas equações não reproduziam a teoria de Newton, como deveria, na situação limite em que o campo gravitacional fosse fraco e estático. Foi em Berlim, onde ele chegou em 1914 para trabalhar na Academia Prussiana de Ciências, que ele viveu um inferno astral, praticamente em estado de choque pois, além de ter que corrigir o erro, ainda estava sofrendo com a separação da esposa que havia levado os filhos com ela para Zurique e a I Guerra tinha começado. No verão de 1915 Einstein tinha ministrado uma série de seis conferências sobre a Relatividade Geral na Universidade de Göttingen onde estava o brilhante matemático alemão David Hilbert (1862-1943). Tendo este tomado conhecimento e se interessado pela Relatividade Geral, ele poderia formulá-la de forma correta e elegante antes do próprio Einstein.

No auge da aflição, Einstein percebeu que havia descrito sua teoria num sistema de coordenadas muito particular, mas que deveria descrever num sistema mais geral. Pois, na Relatividade Geral as leis da Física deveriam valer igualmente para todos os sistemas de coordenadas, fossem eles inerciais ou acelerados, o que tecnicamente equivale a dizer que a Relatividade deveria obedecer ao Princípio da Covariância. Novembro de 1915 foi o mês mais trabalhoso e excitante da vida de Einstein. Ele enviou boletins para a Academia Prussiana de Ciências sobre a reformulação de sua teoria, sendo que a cada semana ele enviava um novo boletim corrigindo os erros e preenchendo as lacunas dos boletins anteriores.

gencial, conforme a força atue perpendicularmente ou tangencialmente à área. Pelo aparecimento da componente tangencial, causadora do cisalhamento, o estresse não pode mais ser descrito por um vetor, com apenas um índice, mas por um tensor de 2 índices, o primeiro referente à direção da normal à área elementar, e o segundo referente às 3 direções do espaço tridimensional. Como o primeiro índice é aplicado às 3 direções ortogonais do espaço, o tensor de estresse forma uma matriz com 3 colunas e 3 linhas, portanto com $3^{2}=9$ elementos. Nesse mesmo sólido deformável, a deformação produzida pelos estresses também pode ser representada por um tensor. Do Cálculo Tensorial faz parte uma álgebra que trata das propriedades dos tensores e das operações matemáticas com eles, com base na qual são formuladas leis físicas, como a "lei de Hooke generalizada" segundo a qual o tensor de estresse é igual ao tensor de deformação multiplicado pelo "tensor de elasticidade", este de ordem 4, portanto com $3^{4}=81$ constantes (a lei de Hooke relaciona a força aplicada numa mola com a deformação sofrida por ela). Na Relatividade Geral, a equação de campo de Einstein relaciona o tensor da curvatura do espaço-tempo com o tensor que representa a distribuição de matéria e energia no espaço-tempo. Como o espaço-tempo tem 4 dimensões o tensor de ordem 2 forma uma matriz com 4 × $4=16$ elementos.

${ }^{54}$ EINSTEIN, Albert and GROSSMANN, Marcel. Entwurf einer verallgemeinerten Relativitätsheorie und einer Theorie der Gravitation. I. Physikalischer Teil von Albert Einstein. II. Mathematischer Teil von Marcel Grossmann, Zeitschrift für Mathematik und Physik, v. 62, n. 3, 225-261, 1913. 
O primeiro boletim foi publicado em 6/11/1915 (EINSTEIN, 1915a) ${ }^{55}$ como se fosse o último. Mas no dia 11 foi publicada uma correção (EINSTEIN, 1915b) ${ }^{56}$. E no dia 18 foi publicado que a nova teoria explicava corretamente o excesso anômalo de 43"/ século na precessão do periélio de Mercúrio $^{57}$ (EINSTEIN, 1915c) ${ }^{58}$ e que a deflexão da luz pelo Sol era o dobro da que ele previra anteriormente. Agora a deflexão da trajetória da luz era vista como encurvamento do espaço-tempo. A partir do bordo do disco solar, o valor da deflexão decrescia linearmente com o aumento da distância ao centro de massa do Sol. Finalmente, no dia 25 apareceram as duas equações de campo da nova teoria na forma correta (EINSTEIN, 1915d) ${ }^{59}$. Agora, para gravidade fraca e velocidades muito menores que a velocidade da luz, as equações de campo se reduziam à conhecida lei da gravitação universal de Newton. A correção para a covariância dependia apenas de retoques finais. Essas equações são as que regem o Universo. Elas mudaram a concepção do Universo. Antes o espaço e o tempo absolutos formavam o palco passivo dos acontecimentos. Agora o espaço-tempo regia a dinâmica do Universo ao se curvar, se dobrar e até se fechar na morte de certas estrelas, fazendo-as sumir do horizonte.

\section{Observações com valor correto}

Uma reação completamente diferente das anteriores ocorreu em 1915, a partir da comunicação que Einstein fez em 18/11/1915 de que a deflexão da luz pelo Sol era de 1,7” (1,74” segundo cálculos mais precisos), o dobro do valor anunciado em 191160. Agora a factibilidade do teste da predição desencadeou uma sucessão de acontecimentos que culminariam no anúncio da confirmação da deflexão gravitacional da luz predita por Einstein e da validade da Relatividade Geral. A deflexão não era mais pela ação de uma força a distância, mas porque a luz, com velocidade constante, percorre geodésicas nulas ${ }^{61}$ num espaço-tempo encurvado pela presença de matéria. Essa concepção do mundo físico irá possibilitar a formulação da Cosmologia Moderna.

${ }^{55}$ EINSTEIN, Albert. Zur allgemeinen Relativitätstheorie, Sitzungsberichte der Königlich Preußischen Akademie der Wissenschaften (Berlin), 778-786, 1915a.

${ }^{56}$ EINSTEIN, Albert. Zur allgemeinen Relativitätstheorie (Nachtrag), Sitzungsberichte der Königlich Preußischen Akademie der Wissenschaften (Berlin), 799-801, 1915b.

${ }^{57}$ Ver nota de rodapé 36.

${ }^{58}$ EINSTEIN, Albert. Erklärung der Perihelbewegung des Merkur aus der allgemeinen Relativitätstheorie, Sitzungsberichte der Königlich Preußischen Akademie der Wissenschaften (Berlin), 831-839, 1915c.

${ }^{59}$ EINSTEIN, Albert. Die Feldgleichungen der Gravitation, Sitzungsberichte der Königlich Preußischen Akademie der Wissenschaften (Berlin), 844-847, 1915d.

${ }^{60}$ Mas, mesmo essa dedução do valor novo e correto foi considerada problemática por EARMAN e GLYMOUR (1980a, pp. 54-55), por ter sido utilizado o Princípio de Huygens que é incompatível com a invariância da velocidade da luz postulada pela Relatividade Geral.

${ }^{61}$ Geodésica nula é a distância de separação entre dois pontos do espaço-tempo percorrida pela luz. No formalismo matemático o intervalo de tempo envolvido é nulo, daí a denominação geodésica nula. Já o caminho mais curto no espaço-tempo percorrido por uma partícula dotada de massa, que viaja portanto a uma velocidade menor que a da luz, é caracterizado por um intervalo tempo não nulo e positivo. 
Durante a I Guerra Mundial os ingleses não tinham muito conhecimento das atividades científicas na Alemanha e nos países Austro-Húngaros, pois a colaboração entre os cientistas desses países esteve interrompida e, consequentemente, a comunicação direta entre os cientistas alemães de um lado, e cientistas ingleses, franceses e americanos de outro, também estava interrompida.

Mas em 1905 Eddington tinha sucedido o astrônomo Frank W. Dyson (1868-1939) no posto de Assistente Chefe do Observatório de Greenwich. Dyson fôra nomeado Astrônomo Real da Escócia. Possivelmente nessa ocasião Eddington e Dyson se conheceram. Mas, em 1910 Dyson se tornou o nono Astrônomo Real da Inglaterra. Eddington, por sua vez, se tornou professor da Universidade de Cambridge em 1913 e diretor do Observatório daquela Universidade em 1914. Ele era um jovem brilhante da astronomia britânica e Dyson teria se considerado seu mentor (EARMAN AND GLYMOUR, 1980a, p. 71) ${ }^{62}$. Assim, quando Eddington deixou Greenwich e foi para Cambridge, deixou para trás a Astronomia de Posição, o estudo dos movimentos próprios ${ }^{63} \mathrm{e}$ da distribuição espacial das estrelas, que envolviam a prática astronômica com o uso de telescópios e instrumentos de medição de placas fotográficas e a análise de dados, passando então a se dedicar à Astrofísica Teórica. Esta última disciplina dava os primeiros passos nos promissores estudos sobre a estrutura e constituição das estrelas. Em 1917 Eddington já tinha angariado prestígio científico inclusive por seus estudos em Astrofísica Estelar. Também por estar frequentemente envolvido, desde 1916 até o fim de sua vida em 1944, em famosas controvérsias, geralmente rudes e pouco cavalheirescas com colegas, mas sempre espirituosas e que, por isso, atraíam grande audiência nas reuniões da Royal Astronomical Society (RAS), Eddington já era famoso e bastante conhecido, mesmo antes do eclipse de 1919.

Reconhecido como importante astrofísico de Cambridge e tendo na bagagem a experiência de um astrônomo observacional (WILL, 2015) ${ }^{64}$, em 1916 Eddington se tornou secretário da RAS. Por ocupar essa posição, foi um dos primeiros a receber privadamente em fevereiro de 1916 do cosmólogo e colega holandês, Willem de Sitter (1872-1934), um pacote contendo os recentes artigos de Einstein sobre a Relatividade Geral já traduzidos ao inglês. Assim, logo ele soube da nova teoria de Einstein e do valor corrigido da deflexão da luz. Foi quando ele teria cogitado em fazer as observações no próximo eclipse solar para comprovar a predição de Einstein, embora para ele, como veremos, a Relatividade Geral fosse correta, assim como a predição da deflexão da luz.

62 EARMAN, J. and GLYMOUR, C. Ibid., 1980a, p. 71.

${ }^{63}$ Movimento próprio é a componente do movimento de uma estrela no espaço, que se projeta no plano do céu, ou seja, no plano perpendicular à linha de visada.

${ }^{64}$ WILL, Clifford M. The 1919 measurement of the deflection of light, Classical and Quantum Gravitation, v. 32, 124001, 1-17, 2015. arXiv:1409.7812 [physics.hist-ph] 2015. Acesso em 12/1/19. 
O próximo eclipse seria em 8/6/1918 e a faixa da totalidade cruzaria de $\mathrm{O}$ a L todo o território norte-americano. Mas, por causa da Guerra, Eddington não podia viajar para os EEUU. Por isso consultou Campbell se ele poderia tentar novamente fotografar o eclipse. Campbell concordou, mas seus equipamentos tinham sido confiscados pelos russos em $1914 \mathrm{e}$ isso o forçou a improvisar o telescópio com itens que estavam disponíveis no Observatório de Lick. As observações foram feitas em Goldendale, WA (CAMPBELL, 1918) ${ }^{65}$ com ajuda de Curtis na Expedição Crocker ${ }^{66}$. Embora as condições meteorológicas tivessem sido boas para observar o eclipse, Campbell tirou as fotografias com equipamento inadequado. Quando ele pediu para Curtis fazer medições nas placas, este concluiu que as estrelas estavam praticamente na mesma posição, não tinham se deslocado, de modo que Einstein estaria errado. Mas, para Campbell o anúncio taxativo desse resultado poderia solapar o projeto de Eddington, além de colocar em risco a reputação do Observatório de Lick do qual era diretor, principalmente por saber que o instrumento inadequado poderia ter influído no resultado. Como veremos, Campbell fez uma comunicação preliminar na RAS em 11/7/1919 especulando que os resultados obtidos por ele descartavam o valor predito por Einstein (ALMASSI, 2009, p. 60) ${ }^{67}$.

\section{O eclipse de 29/5/1919}

Em 1917, quando começaram os preparativos da expedição britânica para o eclipse de 1919, Dyson era a figura astronômica mais influente da Grã-Bretanha. Em 1918 Eddington preparou um apanhado detalhado, persuasivo e laudatório sobre a Relatividade Geral de Einstein e suas aplicações para a Physical Society of London (WILL, 2015, p. 3-4) ${ }^{68}$. Depois de alertar Dyson para a importância da Relatividade Geral, associou-se a ele para organizarem uma expedição para medir a deflexão da luz num eclipse solar. Atraído pelo fato de que o Sol estaria à frente do rico aglomerado estelar das Híades, da constelação do Touro, Dyson propôs que a expedição fosse feita para o eclipse total do Sol de 29/5/1919. Ele obviamente também tinha experiência profissional consolidada na Astronomia Observacional, pois tinha trabalhado na área de paralaxe estelar ${ }^{69}$ em que tinha que fazer a análise fotográfica de diminutos deslocamentos angulares de

${ }^{65}$ CAMPBELL, W. W. The Total Solar Eclipse of June 8, 1918-Position of Observing Station and Times of Contacts, Lick Observatory Bulletin, v. 10, n. 317, 1-3, 1918.

${ }^{66} \mathrm{O}$ californiano William H. Crocker (1861-1937), banqueiro, político influente e grande benfeitor, patrocinou a expedição desse e de outros eclipses. Ele era membro do Conselho de Regentes da Universidade da Califórnia à qual pertencia o Observatório de Lick.

${ }^{67}$ ALMASSI, Ben. Trust in expert testimony: Eddington's 1919 eclipse expedition and the British response to general relativity, Studies in History and Philosophy of Modern Physics, v. 40, 57-67, 2009, p. 60.

68 WILL, Clifford M. Ibid., 2015, pp. 3-4.

${ }^{69}$ Para ilustrar didaticamente o fenômeno da paralaxe, sugiro que o leitor estenda um dos braços para a frente, aponte o dedo indicador para cima e, em seguida, veja que o dedo muda de posição em relação aos objetos mais distantes do fundo quando é visto só com o olho direito ou só com o olho esquerdo. Paralaxe é a mudança da posição aparente de um objeto quando se muda o ponto de onde ele é observado. No exemplo dado, a distância de separação dos dois olhos é pequena, o que permite perceber a paralaxe só de objetos bem próximos. Uma distância bem maior entre os dois locais de observação é necessária para conseguirmos medir o pequeno ângulo da paralaxe das estrelas mais próximas em relação ao fundo de estrelas bem mais distantes que, por isso mesmo, aparentam fixas. Para a paralaxe de uma estrela próxima uma observação é feita numa data e, cerca de 6 meses depois, é feita a segunda observação porque, assim, 
estrelas. Analisando em fotografias de um eclipse ocorrido em Sfax, na Tunísia, em 1905, o brilho de estrelas de Híades até cerca de 6 raios solares ${ }^{70}$ do centro do disco solar, ele concluiu que, revelando as placas de forma adequada e contando com condições meteorológicas equivalentes às de Sfax, a objetiva do telescópio equatorial astrográfico ${ }^{71}$ do Observatório de Greenwich, utilizado em 1905, seria capaz de detectar no eclipse de 1919 os pequenos desvios angulares preditos por Einstein em não menos que 13 estrelas brilhantes angularmente próximas ao Sol (DYSON, 1917) ${ }^{72}$. Este artigo pode ser considerado o pontapé inicial para a organização da expedição britânica para o eclipse em Sobral e Ilha do Príncipe. Pouco depois o Governo Britânico concederia um financiamento de $100 £$ para os instrumentos e 1 mil $£$, para a expedição, o que é notável face à escassez de recursos decorrente da Guerra.

Em 11/11/1918 terminava a I Guerra. Isso removeria os óbices para viagens internacionais dos astrônomos britânicos. Mas Eddington era um quacre ${ }^{73}$ devoto e, como tal, já tinha pedido dispensa do serviço militar por “objeção de consciência”. Ele era um conscientious objector. Por causa da I Guerra, desde 1917 as autoridades britânicas, necessitando desesperadamente de mais homens, apelavam das dispensas e tornavam o recrutamento obrigatório para todos os homens fisicamente aptos. Para Eddington foram realizadas três audiências e, em caso de insucesso, o destino de Eddington seriam os trabalhos forçados. Mas, da última audiência participou Dyson, cujo apelo conseguiu tirar Eddington do recrutamento e dos trabalhos forçados. A proposta foi a de que ele chefiaria uma expedição científica, algo que lhe interessava. Por outro lado, isso daria às autoridades uma saída honrosa sem arruinar a carreira científica de Eddington. Assim a Ciência salvou a carreira de Eddington, mas este, em nome de seu pacifismo, aspirava a que a comunidade científica das Potências Aliadas voltasse a bons termos com a das Potências Centrais, especialmente com a da Alemanha submetida a uma atmosfera antigermânica.

\footnotetext{
a Terra se encontra na órbita ao redor do Sol em duas posições diametralmente opostas, ou seja, a separação entre os dois pontos de observação (a linha de base) tem cerca de 2 UA (Unidade Astronômica), duas vezes a distância média da Terra ao Sol, de 150 milhões km. Mas a paralaxe estelar é a metade dessa separação angular porque, por definição, ela é definida para uma linha de base de 1 UA. A maior paralaxe estelar, que é da estrela mais próxima (Proxima do Centauro) é de apenas 0,77 ".

${ }^{70}$ Num eclipse total do Sol é praticamente impossível obter uma boa imagem fotográfica de uma estrela que esteja a menos de 1 raio solar do bordo do disco solar, pois aí o brilho da coroa solar ainda é intenso e tende a obliterar a estrela. Contudo, também é difícil obter uma boa imagem de uma estrela que esteja a mais de 5 raios solares, desta vez pela falta de qualidade óptica das objetivas a essas distâncias radiais, especialmente quando as objetivas são lentes simples, como as usadas no eclipse de 1919. Assim, a região favorável ao redor do Sol se confina entre 1 e 5 raios solares a partir do bordo solar.

${ }^{71}$ Para elaborar catálogos estelares eram utilizados telescópios astrográficos, dotados de lentes cujo campo visual era capaz de abranger grande extensão angular (tipicamente alguns graus). Esses telescópios eram equatoriais quando instalado numa montagem capaz de acompanhar o movimento diurno, de L para $\mathrm{O}$ dos astros.

72 DYSON, F. W. On the Opportunity afforded by the Eclipse of 1919 May 29 of verifying Einstein's Theory of Gravitation, Montlhly Notices of the Royal Astronomical Society, v. 77, 445-447, 1917.

${ }^{73}$ Membro de um grupo religioso resultante de um movimento protestante britânico do século 18, que defende o pacifismo, a simplicidade de vida e a filantropia.
} 
A faixa de totalidade do eclipse de 1919, pela qual passaria a sombra do Sol inteiramente eclipsado pela Lua, se estendia de O para L a partir da América do Sul, cruzando depois o Atlântico Sul rumo à África Central. Na América do Sul passaria pelo Peru e norte do Chile, Bolívia, Centro-Oeste e Nordeste do Brasil, incluindo o semi-árido cearense. Na África essa faixa tangenciaria o sul da Libéria, da Costa do Marfim e de Gana, passando pela Ilha do Príncipe e atravessando o território africano pelo Gabão, Congo, República Democrática do Congo, nordeste de Zâmbia, norte de Malawi, Tanzânia e nordeste do Moçambique.

\section{Técnica observacional. Análise dos dados}

A observação num eclipse da deflexão da luz de uma estrela pelo Sol constituía um desafio e tanto se considerarmos os recursos tecnológicos disponíveis em 1919. A técnica observacional utilizada fez uso da fotografia que, para os astrônomos, tinha chegado em meados do século 19, sendo progressivamente aperfeiçoado nas décadas seguintes (BARNARD, 1898)74. Mas na década de 1980, o atualmente popular CCD (Charge-Coupled Device) encontradiço hoje em todas câmeras digitais de imagem, praticamente aposentou a fotografia astronômica. Por isso, para os astrônomos mais jovens de hoje, termos técnicos como pixel, corrente de escuro, eficiência quântica etc. são familiares, mas não os termos de um passado nem tão remoto como placa, exposição de placa, medição de placa, emulsão, saturação, solarização, revelação etc.

Considerando que o leitor queira entrar no mérito da discussão se as fotografias do eclipse de 1919 comprovaram, ou não, a deflexão da luz predita por Einstein, apresento um breve esclarecimento sobre métodos, técnicas, dispositivos suplementares etc. que eram usados na obtenção, revelação, secagem, medição e análise das fotografias.

Nos instantes da totalidade do eclipse solar, a Lua esconde totalmente o Sol e o céu fica praticamente sem a claridade diurna, o que possibilita enxergar as estrelas, inclusive aquelas que se encontram no campo visual próximo ao Sol. Usando um telescópio acoplado a uma câmera com placas fotográficas, os astrônomos fotografavam o Sol eclipsado e as estrelas que apareciam ao seu redor.

No presente caso, o objetivo da observação era detectar e medir a deflexão da luz estelar causada pelo Sol. Quando observamos estrelas noturnas no céu, grosso modo. à exceção das estrelas mais próximas, a vasta maioria forma um padrão fixo, praticamente imutável na esfera celeste. Assim, cada estrela pode ser posicionada com precisão ao ser referenciada a estrelas vizinhas. Porém, o Sol é um astro relativamente próximo, é membro do Sistema Solar. Por isso o Sol,

\footnotetext{
${ }^{74}$ BARNARD, Edward E. The Development of Photography in Astronomy, Publications of the Astronomical
} Society of the Pacific, v. 10, n. 65, 213-222, 1898. 
assim como a Lua e os planetas do Sistema Solar, não mantêm posição fixa em relação às estrelas noturnas, mas se movem em relação a elas. Num eclipse total do Sol alguma estrela noturna poderá ser vista perto do disco solar, o que não significa que essa estrela tenha literalmente se aproximado do Sol, mas apenas que ela, que se encontra muito, muito além do Sol, por efeito de perspectiva é vista da Terra angularmente perto do bordo do Sol. Nessa situação, um raio de luz proveniente dessa estrela passa realmente pelas proximidades do Sol e, pelo efeito da deflexão predito por Einstein, a trajetória da luz em vez de ser retilínea, sofre um pequeno desvio. Ora, sempre que vemos uma estrela, vemo-la na direção de onde a luz dessa estrela chega até nós e, se essa direção é alterada por causa da deflexão pelo Sol, a estrela será vista na esfera celeste numa direção diferente. A deflexão da luz fica registrada na fotografia do eclipse na forma de um deslocamento da posição da estrela na placa fotográfica, deslocamento esse que não ocorre numa fotografia dessa mesma estrela tirada fora do eclipse. Portanto a deflexão pode ser quantificada diferencialmente, através da comparação da posição de uma mesma estrela fotografada no eclipse (placa do eclipse) e fora dele (placa de comparação).

A deflexão angular máxima (quando a estrela se encontra idealmente no bordo do disco solar) é de apenas 1,75". A deflexão decresce segundo o inverso da distância ao centro do disco solar. A observação em solo de um fenômeno com essa minúscula amplitude angular, inevitavelmente envolve múltiplas interferências que nada têm a ver com a própria deflexão. Algumas dessas interferências podem ser calculadas e removidas. Por exemplo, há o fenômeno astronômico da aberração da luz ${ }^{75}$ que pode ser calculada para cada estrela em função de suas coordenadas na esfera celeste e do instante da observação. Este é um efeito que pode ser removido da observação bruta por cálculo. Outro efeito que pode ser, não calculado com exatidão, mas estimado na média, é a refração atmosférica. Este é um efeito devido à atmosfera da Terra. O ar tem um índice de refração muito próximo da unidade (índice de refração do vácuo), mas é levemente maior que 1. Embora para a luz visível seja maior que 1 só na quarta casa decimal, assim mesmo a atmosfera refrata os raios de luz provenientes das estrelas. Como o ângulo da refração depende da densidade e, na atmosfera, a densidade do ar decresce com a altitude, a refração causada na luz das estrelas pela nossa atmosfera é diferencial. De um modo geral, a refração diferencial da atmosfera faz uma estrela parecer mais elevada em relação ao horizonte, do que realmente está. Esse efeito é máximo no horizonte e diminui com a elevação até se anular na

75 A aberração estelar é um fenômeno que faz com que uma estrela seja vista numa posição diferente daquela em que ela realmente se encontra. Ela é devida a que, quando fazemos a observação da Terra, não estamos parados, mas estamos orbitando com a Terra ao redor do Sol. À semelhança de uma chuva que cai verticalmente, mas aparenta estar caindo obliquamente contra nós quando nos pomos a correr, a luz proveniente de um astro também muda de direção em função da direção e da velocidade do movimento orbital da Terra. A amplitude da aberração é determinada pela razão entre a velocidade orbital da Terra e a velocidade da luz que é de cerca de 20 ". Uma estrela situada supostamente no prolongamento de uma reta que passa pelo Sol e é perpendicular à eclíptica (plano da órbita da Terra), descreverá ao longo do ano um círculo com diâmetro que é o dobro da amplitude acima: 2 x $20 "=40 "$ " Na aberração vemos projetado no céu o nosso próprio movimento orbital ao redor do Sol. Estrelas a latitudes menores que $90^{\circ}$ em relação à eclíptica, descreverão elipses e, finalmente, estrelas que se encontram na própria eclíptica, descreverão segmentos de reta. Portanto a aberração de uma estrela depende da sua posição no céu e do instante da observação. 
vertical do observador. Como a atmosfera é turbulenta, a refração diferencial varia caoticamente ao longo do tempo, de modo que apenas um valor médio pode ser estimado levando em conta a elevação aparente da estrela acima do horizonte, a altitude do local de observação, a temperatura e pressão durante a observação. Este efeito também é normalmente excluído, ainda que com as limitações apontadas. A correção para os efeitos da aberração e da refração diferencial é rotineira nas observações astronômicas feitas em solo.

Medir a deflexão da luz no eclipse, pela comparação entre duas imagens das mesmas estrelas, uma na placa do eclipse e outra na placa de comparação, constitui um método diferencial padronizado ou ortodoxo (às vezes esse método pode ser modificado, o que efetivamente ocorreu com as placas do eclipse de 191976). As diminutas diferenças de posição de uma mesma estrela nas duas placas são medidas micrometricamente. Infelizmente essas medidas, mesmo corrigidas da aberração e refração diferencial, ainda não são as medidas procuradas da deflexão da luz porque ainda estão contaminadas por vários efeitos espúrios. Mesmo no procedimento ortodoxo, quando as placas do eclipse e as placas de comparação são obtidas no mesmo local (local do eclipse), mas em datas diferentes, as fotografias são tomadas em diferentes direções do céu local, portanto com o telescópio apontando para direções diferentes, o que implica em flexões e torções que podem alterar o comportamento do telescópio. As placas do eclipse e de comparação também são obtidas a diferentes temperaturas ambientes, não só porque as estações são diferentes, mas também porque o eclipse é observado de dia e as estrelas de comparação são fotografadas à noite. A variação da temperatura ambiente se correlaciona com diferentes intensidades da turbulência atmosférica. Esta é causada pelos movimentos caóticos de células convectivas da nossa atmosfera. A refração do ar, de que falamos acima, produz agora o conhecido fenômeno da cintilação das estrelas. Uma fotografia tomada com tempo de exposição mais longo mostrará as estrelas, não como fontes pontuais de luz, mas como borrões extensos e difusos, em que a posição da estrela é afetada de incertezas não desprezíveis. A temperatura ambiente também afeta o desempenho de itens ópticos como espelhos, lentes e placas fotográficas e pode eventualmente deformar o suporte desses itens nos instrumentos.

Sem falar dos problemas imprevisíveis do tempo como chuva, nebulosidade, nuvens intermitentes, poeira em suspensão etc. que podem, não só prejudicar as imagens, mas até mesmo inviabilizá-las, devemos considerar também os problemas instrumentais como desalinhamentos, flexões, torções etc. decorrentes do transporte desde o observatório de origem até lugares remotos de observação. Para facilitar o transporte se optava por instrumentos de menor peso e tamanho, mas isto trazia a desvantagem de instrumentos menos robustos, telescópios com objetivas menores que exigiam tempos de exposição fotográfica mais longos que, por sua

76 Veremos que para as placas do eclipse da Ilha do Príncipe, num estágio intermediário da análise foram utilizadas placas de um campo de estrelas que não era do eclipse, obtidas em Príncipe e também em Oxford. 
vez, dependiam mais criticamente da precisão do sistema de rastreio do Sol que, diferentemente de hoje, era controlado por mecanismo de relojoaria acionado por peso (WALLER, 2002a, p. $54)^{77}$.

Na máquina de medição micrométrica, a diferença de posição de cada estrela na placa do eclipse e na placa de comparação era quantificada no milésimo do milímetro, contando-se o número de voltas de um parafuso micrométrico. Para a comparação podiam ser utilizadas mesas sofisticadas em que as placas comparadas podiam ser sobrepostas e deslocadas ao longo dos eixos ortogonais, $x$ e $y$, e as medidas apareciam num mostrador, aperfeiçoamentos técnicos que agilizavam a tarefa mas que, nem por isso, deixava de ser tediosa e de exigir muita atenção.

O primeiro passo da análise era ter as coordenadas-padrão das estrelas que apareceriam ao redor do Sol no eclipse. Para o eclipse em questão as 13 estrelas selecionadas já apareciam ilustradas em DYSON (1917, p. 446) ${ }^{78}$, assim como em DYSON, EDDINGTON and DAVIDSON (1920, Diagram 1, p. 294) ${ }^{79}$, sendo que esta última publicação traz uma tabela com as coordenadas-padrão dessas estrelas (DYSON, EDDINGTON and DAVIDSON, 1920, Table I, p. 293 ${ }^{80}$. As coordenadas-padrão são medidas nas coordenadas ortogonais $x$ e $y$, paralelas respectivamente ao equador celeste e aos meridianos da esfera celeste. Elas são definidas sobre um plano que coincide com o plano da fotografia (plano fotográfico). Nas coordenadas-padrão, as estrelas posicionadas na esfera celeste através das coordenadas celestes equatoriais (declinação e ascensão reta), são projetadas sobre o plano fotográfico, sendo que este plano é tangente à esfera celeste no ponto para o qual o telescópio está apontado que, no caso, é o centro do disco solar. Sobre uma placa fotográfica as coordenadas ortogonais $x$ e $y$ podem ser medidas a partir de um ponto de origem arbitrário, mas o centro do disco solar é a escolha usual.

Em seguida são feitas as medições da diferença da posição (chamemos desvio), $\Delta x$ e $\Delta y$ de cada estrela para cada par de placas do eclipse e de comparação. Se é utilizado o método estatístico, requer-se uma boa amostragem (bom número de estrelas observadas num bom número de fotografias tiradas durante a totalidade do eclipse). Nesse caso o objetivo não é determinar o desvio de cada estrela com precisão. Uma vez que há incertezas experimentais de diversas origens nas medidas, o número de observações é multiplicado objetivando a obtenção de um resultado final com o valor médio mais provável do desvio, acompanhado de uma margem de incerteza (desvio padrão), a menor possível.

77 WALLER, John. Fabulous Science. Fact and fiction in the history of scientific discovery. New York: Oxford University Press, 2002a, p. 54.

${ }^{78}$ DYSON, F. W. Ibid., 1917, p. 446.

${ }^{79}$ DYSON, F. W., EDDINGTON, A. S. and DAVIDSON, C. Ibid., 1920, Diagram 1, p. 294.

${ }^{80}$ DYSON, F. W., EDDINGTON, A. S. and DAVIDSON, C. Ibid., 1920, Table 1, p. 293. 
Uma vez feitas as medições e coletados os desvios $\Delta x$ e $\Delta y$ das observações, um modelo deve ser concebido e formalizado matematicamente (equações de condição) que dê conta das principais fontes de erros que afetam os desvios $\Delta x$ e $\Delta y$. Por se tratar de erros supostamente pequenos, o modelo permite representá-los na forma de uma combinação linear das próprias medidas $x$ e $y$ das coordenadas-padrão. Assim, duas equações de condição correspondentes aos desvios $\Delta x$ e $\Delta y$ podem ser escritas envolvendo 7 coeficientes (incógnitas), sendo 2 referentes ao erro na origem (ponto zero) das coordenadas (erro de translação), 2 referentes à variação da escala da placa fotográfica (expansão da placa por aquecimento), 2 referentes ao erro direcional das coordenadas $x$ e $y$ (erro rotacional) e 1 que dá conta da deflexão da luz a uma distância padrão do centro do disco solar já que, segundo a predição de Einstein, a deflexão decresce linearmente com a distância ao centro do disco solar. Este último coeficiente fornece a medida procurada da deflexão. Notar que não há coeficientes para a refração atmosférica, nem para a aberração, pois as respectivas correções são geralmente feitas, no fim, na deflexão média (DYSON, EDDINGTON and DAVIDSON, 1920, pp. 306-308) ${ }^{81}$.

Aplicando-se as equações de condição a cada estrela analisada num par de placas, gerase o chamado sistema de equações normais, geralmente sobredeterminado (com mais equações do que incógnitas), o que permite determinar 5 dos coeficientes acima por minimização dos erros quadráticos, já que os dois coeficientes do erro da origem podem ser eliminados fisicamente na medição das placas $^{82}$. A seguir, não se obtém a solução exata, mas a solução otimizada pela minimização dos erros (regressão linear por mínimos quadrados). Os coeficientes são determinados para cada uma das duas coordenadas, para cada par de placas e, no final, é obtido o coeficiente médio para todos os pares de placas, com a respectiva dispersão. Subtraindo da média do coeficiente de deflexão gravitacional obtida do conjunto das placas do eclipse, a mesma média obtida das placas de comparação, se obtém a procurada deflexão já escoimada dos erros considerados no modelo.

A critério dos analistas e de acordo com a conveniência, algum tipo de erro pode ser removido fisicamente durante a medição, o que torna desnecessário calcular estatisticamente os coeficientes desse erro. Além do desencontro da origem das coordenadas num par de placas, o erro de escala também pode ser eliminado com a ajuda de um outro tipo de placa, a placa de escala. Isso, como veremos, foi feito com as placas de Sobral obtidas com o telescópio de 4 polegadas. Na prática, a placa de escala foi uma das placas de comparação obtidas em Sobral com o telescopio de 4 polegadas, porém, com uma diferença tecnica que explicarei adiante.

${ }^{81}$ DYSON, F. W., EDDINGTON, A. S. and DAVIDSON, C. Ibid., 1920, pp. 306-308.

$82 \mathrm{Um}$ expediente prático é tirar vantagem do fato de que o desvio gravitacional da luz decresce segundo o inverso da distância ao centro do disco solar. Então as estrelas mais afastadas do Sol tendem a ocupar a mesma posição tanto na placa do eclipse, quanto na placa de comparação, o que pode melhorar a precisão da sobreposição das duas placas. 


\section{Expedição britânica}

Em reunião de 10/11/1917, o Joint Permanent Eclipse Committee (JPEC) da RS e da RAS decidiu enviar expedições para Sobral e Ilha do Príncipe (DYSON, EDDINGTON and DAVIDSON, 1920) ${ }^{83}$. Os britânicos entenderam que a infraestrutura em Príncipe era melhor para a expedição do que no continente africano. Além das duas objetivas de 13 polegadas com foco de 3,43 m, uma do já citado telescópio astrográfico de Greenwich e outra da Universidade de Oxford, que seriam iluminadas por celóstatos ${ }^{84}$ de 16 polegadas, o astrônomo jesuíta Aloysius L. Cortie (1859-1925) que deveria vir para Sobral, mas acabou não vindo, sugeriu que também fosse levado para Sobral o telescópio de 4 polegadas e foco de 19 pés com o celóstato de 8 polegadas da Royal Irish Academy. Os dois telescópios astrográficos utilizavam placas de $16 \mathrm{~cm}$ x $16 \mathrm{~cm}$, enquanto o telescópio de 4 polegadas utilizava placas de 10 polegadas x 8 polegadas. O astrógrafo de Oxford foi levado para Príncipe e para Sobral o astrógrafo de Greenwich mais o telescópio de 4 polegadas. Este último, levado como mero instrumento sobressalente, foi o que, no fim das contas, salvou a missão observacional de Sobral.

Em 8/3/1919, 4 meses após o armistício que encerrou a Guerra, as duas expedições partiram juntas de Liverpool: Eddington em companhia do relojoeiro Edwin T. Cottingham (1869-1940) para a Ilha do Príncipe, na costa da atual Guiné Equatorial e Andrew C. Crommelin (1865-1939) na companhia de Charles R. Davidson (1875-1970) para Sobral. Estes dois eram assistentes do Observatório de Greenwich. Embora outros países como Alemanha, Estados Unidos e Argentina tivessem tentado há anos detectar a deflexão da luz, como se estivesse escrito nas estrelas, no eclipse de 1919 só os britânicos estavam envolvidos nesse projeto. EARMAN e GLYMOUR (1980a, p. 70) ${ }^{85}$ fizeram esta interessante ponderação:

\footnotetext{
Einstein's frustration, and Freundlich's, are perfectly understandable. Expedition after expedition had returned empty handed. The one that did obtain photographs did not publish the results. Freundlich, who had learned of Campbell's preliminary views about the results of the expedition of 1918, wrote Einstein that the Americans had not been able to demonstrate the light-deflection effect. The eclipse of 1919 was the next hope, but the Lick Observatory could not mount an expedition because of the war. The Argentine Observatory had hoped to send an expedition to Brazil to test Einstein's prediction in 1919, but the government refused to finance it. Freundlich planned an expedition but did not carry it out, probably because of lack of funding. Everything bung on the British, who seem to have won the privilege of photographing the 1919 eclipse almost as a spoil of war.
}

\footnotetext{
83 DYSON, F. W., EDDINGTON, A. S. and DAVIDSON, C. Ibid., 1920.

${ }^{84}$ Celóstato é um instrumento astronômico dotado de dois espelhos planos que, atuando em conjunto, fazem os raios solares incidirem sempre sobre a objetiva de um telescópio fixo, geralmente na posição horizontal, apesar do movimento do Sol no céu. Para isso, o primeiro espelho (considerando o trajeto da luz) gira em torno do eixo polar (paralelo ao eixo da Terra) com metade da velocidade do movimento diurno do Sol. O segundo espelho deve ser apenas ajustável para qualquer direção, precisando ser ajustado poucas vezes durante uma observação.

85 EARMAN, J. and GLYMOUR, C. Ibid., 1980a, p. 70.
} 


\section{Sobral}

Crommelin e Davidson chegaram a Belém, PA, em 23 de março. Para não chegarem a Sobral muito antes da equipe brasileira, decidiram seguir viagem até Manaus para conhecerem a Amazônia. Chegaram a Sobral em 30 de abril. A equipe brasileira, do Observatório Nacional do Rio de Janeiro, chegou a Sobral junto com a equipe norte-americana da Carnegie Institution, no dia 9 de maio. Ela deu apoio logístico às expedições estrangeiras, mas não fez pesquisa sobre a deflexão da luz. A missão científica do Observatório Nacional era realizar observações em Física Solar, com objetivos claramente distintos da comprovação do efeito Einstein.

A equipe inglesa montou os celóstatos de 16 e de 8 polegadas, cada um com o seu mecanismo de relojoaria acionado a peso para que o celóstato rastreasse o Sol. Na extremidade dos tubos dos dois telescópios ficava a respectiva câmera fotográfica, na qual era inserido com precisão o estojo que protegia a placa fotográfica da luz, exceto nos instantes em que ela era exposta mediante a remoção temporária de um anteparo opaco corrediço.

Para ajustar o foco dos telescópios, a brilhante estrela Arcturus foi fotografada variando-se levemente o foco em torno da posição mais provável. O exame das fotografias do astrógrafo logo mostrou um sério problema de astigmatismo. Para reduzir esse problema, foi colocada uma máscara que obturou a objetiva do telescópio astrográfico de 13 para 8 polegadas, o que atenuou o defeito em boa medida ${ }^{86}$. Daí em diante a máscara foi sempre utilizada. Mas o desempenho desse telescópio ainda iria desapontar os observadores. As imagens do telescópio de 4 polegadas resultaram satisfatórias.

Quanto às condições meteorológicas, no dia 25 de maio houve chuva pesada que foi bem-vinda por baixar a poeira que, até então, tinha sido prejudicial para os mecanismos de relojoaria, apesar de todos os cuidados.

Embora a água fosse escassa em geral, onde a expedição estava alojada havia suprimento ilimitado de boa água. Isso foi benéfico para o processamento das placas fotográficas. Não havia gelo, mas o uso de moringas de barro tornava possível reduzir a temperatura a cerca de $24^{\circ} \mathrm{C}$ e, trabalhando à noite ou de madrugada, era fácil revelar as placas. A água mesmo levemente morna pode molificar e até mesmo arrancar pedaços da emulsão fotográfica inutilizando a placa. Formol foi usado para endurecer os filmes, minimizando assim as chances de deformação da emulsão e, consequentemente da imagem.

${ }^{86}$ Geralmente o defeito óptico de astigmatismo está mais na região periférica de uma lente. Assim a máscara obturadora suprimia da imagem final os raios periféricos da objetiva. 
A manhã do dia do eclipse esteve mais nublada do que na média e a fração de cobertura do céu por nuvens foi estimada em 9/10 no primeiro contato, quando o Sol esteve invisível. Pouco depois o Sol apareceu já um tanto eclipsado pela Lua e ocorreram vários intervalos curtos durante a fase parcial do eclipse, em que o Sol apareceu e possibilitou apontar corretamente os telescópios para o Sol. Justamente quando a totalidade se aproximou, a quantidade de nuvens diminuiu e uma área desobstruída do céu deixou o Sol aparecer 1 min antes do segundo contato. Durante a totalidade de mais de 5 min, o tempo foi contado com a ajuda de um metrônomo e a temperatura ambiente variou pouco, apenas entre 27 e $29^{\circ} \mathrm{C}$. De acordo com a programação, foram expostas 19 placas no telescópio astrográfico com durações alternadas de 5 e $10 \mathrm{~s}^{87}$ e 8 no telescópio de 4 polegadas com tempo mais longo de $28 \mathrm{~s}^{88}$. A região ao redor do Sol esteve livre de nuvens, exceto durante cerca de 1 min perto do meio da totalidade quando o Sol ficou velado por uma tênue nuvem que impossibilitou fotografar as estrelas, mas permitiu registrar a coroa interna do Sol e uma grande protuberância com excelente definição, o que alegrou os que observavam os fenômenos solares. Todas as placas utilizadas permaneceram protegidas em seus estojos à prova de luz, até a revelação que foi realizada em vários lotes nas horas noturnas dos dias seguintes, ficando completada em 5 de junho.

Depois a equipe deixou Sobral para visitar Fortaleza, retornando a Sobral no dia 9 de julho para obter as placas de comparação. Antes de deixar Sobral, os espelhos dos celóstatos e os mecanismos de relojoaria dos mesmos foram removidos e guardados em ambiente fechado para ficarem protegidos da poeira. Já as montagens dos telescópios e dos celóstatos foram deixadas no mesmo local em que estavam instaladas sendo que, antes da remoção, os espelhos receberam marcações para serem recolocados na posição original. As placas de comparação foram obtidas entre 10 e 17 de julho, totalizando 41 exposições no telescópio astrográfico e 18 no telescópio de 4 polegadas mas, uma destas, em vez de ser placa de comparação se tornou placa de escala, tendo a emulsão fotossensível exposta à luz, não diretamente, mas através da placa de vidro (substrato), o que tornaria mais precisa a medição dos desvios das estrelas ${ }^{89}$. Isso foi feito porque essas placas não tinham as dimensões usuais e o respectivo micrômetro era dotado de menos recursos.

\footnotetext{
${ }^{87}$ Em algumas dessas placas apareceram 12 estrelas, em outras 7, mas em 3 placas não apareceram nem mesmo 7 estrelas.

${ }^{88}$ Nessas placas apareceram 7 estrelas mensuráveis, exceto na de número serial 6, quando surgiram nuvens e nenhuma estrela apareceu.

89 Ao fazer a medição dos desvios das estrelas nas placas obtidas com o telescópio de 4 polegadas, cada placa do eclipse foi superposta à placa de escala, de modo que as imagens comparadas ficassem em contato direto, sem a separação pela espessura do substrato de vidro da placa.
} 


\section{Ilha do Príncipe ${ }^{90}$}

De Liverpool até a Ilha da Madeira as duas expedições viajaram juntas. Mas de Madeira, Eddington e Cottingham só puderam partir rumo a Príncipe em 9 de abril, lá chegando no porto de Santo Antonio no dia 23 de abril. A ilha tem apenas $16 \mathrm{~km} \mathrm{x} 10 \mathrm{~km}$ de extensão. Exceto por pouca floresta virgem, a ilha é coberta por plantações de cacau. A expedição chegou no final da estação chuvosa e um vento seco passou a dominar a partir de 10 de maio, sendo que não choveu mais, senão na manhã do eclipse. Foi escolhida uma localidade recomendada pelos locais, a noroeste da ilha chamada Roça Sundy, sede da fazenda principal de um tal Sr. Carneiro, Presidente da Associação dos Produtores que hospedou os astrônomos e, com seus auxiliares, lhes prestou toda assistência. A Roça Sundy fica numa elevação de $150 \mathrm{~m}$ de onde o mar podia ser visto, e ficava o mais afastada possível das elevações que retinham as nuvens. O telescópio foi instalado numa pequena área cercada, adjacente à casa, de onde o chão descia rapidamente em direção ao mar, na direção do Sol no eclipse. No lado oposto o telescópio ficava protegido por uma construção.

A bagagem chegou de trem a Sundy em 28 de abril, mas no trecho final a carga teve que ser transportada por carroça. A instalação dos equipamentos foi feita lentamente, pois não havia interesse em desempacotar logo o espelho e os instrumentos para expô-los desnecessariamente à umidade. Mas os primeiros testes fotográficos começaram em 16 de maio quando houve dias de céu claro e as noites geralmente eram claras.

O celóstato foi instalado num pilar de pedra especialmente construído para essa finalidade. O relógio acionado a peso para movimentar o celóstato foi instalado sobre uma escavação em que o peso podia descer o suficiente para funcionar até $36 \mathrm{~min}$ sem receber corda. A objetiva do telescópio também foi obturada de 13 para 8 polegadas e assim utilizada para todas as fotografias. Uma série de fotografias de uma estrela brilhante (Arcturus), com tempo de exposição de $1 \mathrm{~s}$, certificou que não ocorriam oscilações indesejáveis do telescópio após a colocação da placa. A exposição da placa era feita movendo um anteparo opaco na frente da objetiva, sem nenhum contato direto com o telescópio. Nos ajustes foi dada especial atenção ao paralelismo entre a objetiva e a placa e aos preparativos para o apontamento correto do telescópio ao campo desejado. A focalização foi ajustada através de fotografias de estrelas e, como a temperatura se manteve uniforme, ela foi mantida nas observações.

Os dias que precederam o eclipse foram bastante nublados. Na manhã do eclipse ocorreu uma forte tempestade entre 10 h e 11 h 30 m locais, uma ocorrência extraordinária naquela época do ano. Mas, segundo os cálculos, o início da totalidade seria às 14 h $13 \mathrm{~m} 5 \mathrm{~s} \mathrm{com} \mathrm{duração}$

${ }^{90}$ Em 1919 Príncipe era colônia portuguesa. Desde 1975 as ilhas de São Tomé e Príncipe passaram a constituir um estado independente chamado República Democrática de São Tomé e Príncipe. 
de $5 \min 2 \mathrm{~s}$. Depois da tempestade o Sol apareceu por alguns minutos, mas as nuvens se juntaram de novo. Cerca de meia hora antes da totalidade o crescente solar foi visto ocasionalmente e por volta de $13 \mathrm{~h} 55 \mathrm{~m}$ ele pôde ser visto continuamente entre nuvens à deriva. Durante a totalidade foram feitas as exposições programadas e obtidas 16 placas. Olhando as estrelas que aparecem nas fotografias, parece que as nuvens se dissiparam consideravelmente durante o último terço da totalidade.

Para a revelação das placas em Príncipe, também foi necessário um cuidado com relação à temperatura elevada da água. Antes do eclipse não houve problema porque havia suprimento local de gelo. Mas esse suprimento falhou depois do eclipse e formol teve que ser utilizado para enrijecer a emulsão fotográfica. As placas que aceitavam bem esse tratamento foram reveladas em Príncipe à noite, quando a temperatura era mais baixa, e a secagem foi acelerada com o uso de álcool. Já as demais placas foram mantidas nos respectivos estojos, para serem reveladas depois do retorno da expedição.

Pretendia-se fazer lá mesmo todas as medições das placas reveladas, mas uma greve na companhia de navegação tornou necessário regressar na primeira embarcação, a fim de que os membros da expedição não ficassem retidos na ilha por vários meses. A expedição deixou Príncipe no dia 12 de junho, chegando a Liverpool em 14 de julho. Mas, não foi por isso que não foram obtidas em Príncipe as placas de comparação fora do eclipse, como pôde ser feito em Sobral. É que em Príncipe a totalidade ocorreu mais tarde, no horário local. Nesse caso, para o campo de estrelas próximo ao Sol no eclipse ser visto novamente, fora do eclipse, antes do amanhecer e aproximadamente na mesma posição no céu, seria preciso esperar muitos meses.

Para estimar e eliminar os erros sistemáticos, a falta de placas de comparação foi com-

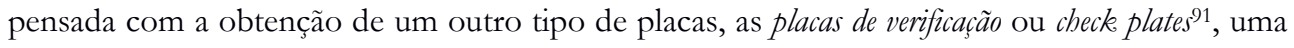
parte em Oxford e outra em Príncipe. Nessas placas o campo de estrelas fotografado incluía a brilhante estrela Arcturus. Esse campo tinha praticamente a mesma declinação do campo do eclipse, o que ajudava a tornar similar o assestamento do telescópio nas duas localidades. Também se tomou o cuidado de fotografar esse campo quando estivesse aproximadamente com a mesma elevação tanto em Oxford quanto em Príncipe. Um ponto positivo dessas placas para o controle do experimento era que elas foram obtidas à noite tanto em Oxford como em Príncipe, evitando assim a influência do aquecimento do espelho e do telescópio pelo Sol.

Das placas de verificação, 5 foram obtidas em Prícipe nas noites de 22 e 25 antes do eclipse, e 5 em Oxford, antes da partida da expedição em 16, 17 e 23 de janeiro (topo da Tabela

91 As placas de comparação, como vimos, continham estrelas vizinhas ao Sol no eclipse. Já as placas de verificação continham estrelas de uma outra região do céu. Para detectar a deflexão da luz, estas placas serviam principalmente para analisar eventuais variações de escala. 
em DYSON, EDDINGTON and DAVIDSON, 1920, p. 315) ${ }^{92}$. Portanto quando Eddington partiu para Príncipe, ele já tinha as placas de verificação obtidas em Oxford para levá-las a Príncipe. Adicionalmente, conforme a Tabela em DYSON, EDDINGTON and DAVIDSON (1920, p. 316 ${ }^{93}$, ele já tinha obtido também em Oxford, nas noites de 16 e 22 de janeiro e de 9 de fevereiro, 5 placas de comparação com o campo estelar do eclipse.

\section{Análise das placas. Resultado}

O resultado final apresentado ao público, das observações da expedição britânica a Sobral e Príncipe, definitivamente não foi um resumo direto da análise dos dados, mas uma construção engenhosamente articulada de uma seleção de conclusões parciais obtidas ao longo da análise. Na tentativa de facilitar ao leitor a compreensão da argumentação de Eddington e sua equipe, seguirei em linhas gerais a narrativa que Eddington publicou um ano depois em EDDINGTON (1920, pp. 101-112) ${ }^{94}$, mas utilizarei o artigo DYSON, EDDINGTON e DAVIDSON $(1920)^{95}$ para dar os detalhes da análise dos dados.

Ainda em Príncipe, uma de apenas duas fotografias aproveitáveis do eclipse pôde ser revelada. Essas fotografias tinham sido obtidas através de reflexão pelo espelho do celóstato. Mas Eddington tinha levado a placa de comparação do mesmo campo de estrelas fotografado diretamente (isto é, sem reflexão pelo espelho) através da objetiva do telescópio de Oxford, antes da viagem. Quando as placas do eclipse de Príncipe e de comparação de Oxford foram superpostas, as emulsões (portanto as imagens) ficaram em contato direto, o que era ideal para a medição dos desvios de cada estrela. Com um micrômetro levado a Príncipe, Eddington fez a medição dos desvios $\Delta x$ e $\Delta y$ de 5 estrelas. Descontos para a refração atmosférica, aberração, orientação da placa etc., que são rotineiros na determinação da paralaxe estelar e com os quais Eddington tinha familiaridade foram feitos e ele concluiu: The results from this plate gave a definite displacement, in good accordance with Einstein's theory and disagreeing with the Newtonian prediction. Althought the material was very meagre compared with what had been hoped for, the writer (who it must be admitted was not altogether unbiassed) believed it convincing (EDDINGTON, 1920, p. 106) ${ }^{96}$. Notar a confissão espontânea de viés. Este primeiro resultado tão promissor deve ter ajudado a consolidar em Eddington uma postura mental otimista que, de fato, ele já tinha e manteve durante toda a análise. Segundo o testemunho do indiano Subramanyan Chandrasekhar (1910-1995), Prêmio Nobel de Física de 1983 que conviveu academicamente no início de sua carreira com Eddington, a fé deste

92 DYSON, F. W., EDDINGTON, A. S. and DAVIDSON, C. Ibid., 1920, p. 315.

${ }^{93}$ DYSON, F. W., EDDINGTON, A. S. and DAVIDSON, C. Ibid., 1920, p. 316.

${ }^{94}$ EDDINGTON, Arthur S. Weighing Light, Chapter VII, Space Time and Gravitation. An outline of the general relativity theory, London: Cambridge University Press, 1920, pp. 101-112.

${ }^{95}$ DYSON, F. W., EDDINGTON, A. S. and DAVIDSON, C. Ibid., 1920.

${ }^{96}$ EDDINGTON, Arthur S. Ibid., 1920, p. 106. 
na teoria de Einstein era incondicional, pois teria dito a Chandrasekhar que, se o envio das expedições para o eclipse dependesse dele, ele não as teria enviado since be was fully convinced of the truth of general relativity (CHANDRASEKHAR, 1983, p. 25) ${ }^{97}$.

Quatro placas do eclipse que não puderam ser reveladas em Príncipe, foram reveladas em Cambridge e só uma delas mostrou estrelas em quantidade suficiente. As medições dessa segunda placa feitas também por Eddington em 22 e 23 de agosto, seguiram o mesmo procedimento usado na placa anterior e também teriam confirmado a predição de Einstein.

Mas, neste ponto, Eddington diz que se preocupou se algum problema instrumental não teria produzido uma falsa deflexão, um simulacro. Foi um recuo cautelar. Para responder a essa dúvida Eddington apelou para as placas de verificação que fotografaram em Príncipe e em Oxford um mesmo campo estelar, mas que não era o do eclipse. Eram 5 placas de Príncipe e 5 de Oxford, com as quais Eddington formou pares e ele próprio fez as medições. Os desvios $\Delta x$ e $\Delta y$ (Príncipe - Oxford) foram medidos para cada estrela (13 no total) nos 5 pares de placas. Esses desvios foram modelados pelas equações de condição e seus coeficientes (desta vez sem os da deflexão da luz) foram obtidos por mínimos quadrados pelas equações normais. Com esses coeficientes foram calculados os residuais para cada uma das 13 estrelas. Tirando a média de todos os residuais concluiu-se que o erro provável na medição de $\Delta x$ e $\Delta y$ era de apenas $\pm 0,22$ ". Com base nesse resultado concluiu não haver erros sistemáticos significativos:

The primary purpose of the check plates is thus fulfilled. They show that photographs of a check. field of stars taken at Oxford and Principe show none of the displacements which are exbibited by the photographs of the eclipse field taken under precisely similar instrumental conditions. The inference is that the displacements in the latter case can only be attributed to presence of the eclipsed sun in the field (DYSON, EDDINGTON and DAVIDSON, 1920, p. 319) ${ }^{98}$.

E ainda acrescentou:

That seems to be satisfactory evidence that the displacement observed during the eclipse is really due to the sun being in the region, and is not due to differences in instrumental conditions between England and Principe. Indeed the only possible loophole is a difference between the night conditions at Principe when the check-plates were taken, and the day, or rather eclipse, conditions when the eclipse photographs were taken. That seems impossible since the temperature at Principe did not vary more than $1^{\circ}$ between day and night (EDDINGTON, 1920, pp. 106-107) ${ }^{99}$.

O uso de placas de verificação para as imagens de Príncipe foi inconvencional e constituiu an extraneous determination of scale (DYSON, EDDINGTON and DAVIDSON, 1920, p.

${ }^{97}$ CHANDRASEKHAR, S. Eddington, the most distinguished astrophysicist of his time, Cambridge: Cambridge University Press, 1983, p. 25.

${ }^{98}$ DYSON, F. W., EDDINGTON, A. S. and DAVIDSON, C. Ibid., 1920, p. 319.

${ }^{99}$ EDDINGTON, Arthur S. Ibid., 1920, pp. 106-107. 
$330)^{100}$, mas permitiu obter a variação da escala livremente do fato complicador de que nas placas do eclipse, ela imita a deflexão gravitacional da luz, uma vez que ambas afastam as estrelas do centro do disco solar (KENNEFICK, 2009, p. 39) ${ }^{101}$, apesar de que, enquanto a deflexão decresce segundo o inverso da distância radial, a variação da escala cresce linearmente com ela.

A análise das duas placas do eclipse foi então retomada, sendo comparadas com as placas de comparação de Oxford, desta vez, contendo o campo estelar do eclipse, e levando agora em consideração o erro de escala obtido anteriormente de forma independente. Embora em Príncipe essas placas tivessem sido feitas de dia, durante o eclipse, Eddington se fiou de novo em que a variação da temperatura durante o eclipse tinha sido mínima. Segundo ele a temperatura ambiente em Príncipe gozou de uma extraordinária estabilidade. Com isso justificou sua hipótese de que a variação de escala era a mesma que a encontrada antes com as placas de verificação e, assim, presumiu ter medido a deflexão da luz para cada estrela. Com base em 5 estrelas foram feitas 4 determinações da deflexão da luz cuja média foi 1,61” \pm 0,30” (DYSON, EDDINGTON and DAVIDSON, 1920, p. 328) ${ }^{102}$, valor bem próximo da predição de 1,75", o que tornava muito improvável a metade desse valor predita pela teoria newtoniana.

Nesta altura dos acontecimentos, para Eddington a questão já parecia resolvida além de qualquer dúvida e, assim, ele aguardava o retorno da expedição de Sobral que lá permaneceu mais dois meses para obter, de madrugada, tanto com o astrógrafo quanto com o telescópio de 4 polegadas, as placas de comparação.

Apesar da obturação da objetiva do astrógrafo, que melhorou seu desempenho óptico, as fotografias foram surpreendentemente desapontadoras, pois, desse telescópio eram esperadas as melhores imagens. As estrelas, longe de serem pontuais, apareceram difusas e extensas, como se estivessem fora de foco e arrastadas por irregularidades no rastreio. Segundo os observadores, na noite anterior ao eclipse o foco estava perfeito. Esse problema desapareceu quando foram tiradas as fotografias de comparação depois do eclipse, sem que nenhum reajuste fosse feito. De fato, as placas de comparação não apresentaram nenhum problema de foco. Os observadores concluíram que se tratava de um problema temporário e o atribuíram a uma expansão não uniforme do substrato do espelho, causada pela incidência dos raios solares, não sendo possível saber se além de possível astigmatismo que causa indefinição da imagem, teria ocorrido também perda de foco que altera a escala das placas, além de também causar indefinição na imagem. $\mathrm{Na}$ prática era impossível discriminar esses efeitos porque, definitivamente, as imagens tinham baixa qualidade, o que dificultava a medição dos desvios.

100 DYSON, F. W., EDDINGTON, A. S. and DAVIDSON, C. Ibid., 1920, p. 330.

${ }^{101}$ KENNEFICK, Daniel. Testing relativity from the 1919 eclipse - a question of bias, Physics Today, v. 62, n. 3, 37-42, 2009, p. 39.

102 DYSON, F. W., EDDINGTON, A. S. and DAVIDSON, C. Ibid., 1920, p. 328. 
Apesar do pessimismo confesso dos próprios observadores, essas placas foram as primeiras a serem medidas após o regresso. Dada a má qualidade das imagens, medidas foram tomadas só na coordenada $y$, já que na coordenada $x$ eram ainda menos confiáveis. Supondo que o erro dominante fosse de focalização (e consequentemente de escala), com base em 6 estrelas de 16 placas do eclipse e 9 placas de comparação, o valor médio da deflexão resultou ser 0,93 ”, sem estimativa do erro provável (DYSON, EDDINGTON and DAVIDSON, 1920, p. 312) ${ }^{103}$. Esse valor é cerca da metade do valor que seria obtido com o telescópio de 4 polegadas e, além disso, mais próximo da previsão da teoria newtoniana.

No curso da análise que estava sendo feita, esse resultado foi perturbador, especialmente para Eddington, pois era muito discrepante daquele que ele tinha obtido com as placas de Príncipe nas quais ele depositava total confiança.

Apesar das reservas em relação às imagens do astrógrafo de Sobral, era difícil invalidálas, tendo em vista o escasso material de Príncipe e a relativa abundância de dados colhidos sob o céu aberto de Sobral. Além disso, as imagens de Príncipe também não eram bem definidas e estavam esmaecidas pela nebulosidade (mas Eddington converterá depois a presença dessa nebulosidade geral em vantagem a favor das placas de Príncipe!).

Apesar dessas debilidades das placas de Príncipe, Eddington atribuiu a elas uma alta confiabilidade argumentando que o número maior de placas e de estrelas de Sobral era menos relevante porque a questão em discussão era de erro sistemático ${ }^{104}$, além dos fatos de que duas estrelas nas placas de Príncipe estavam perto da posição de deflexão máxima (estrelas adicionais em outras posições contribuíam menos); e a detecção em Sobral de estrelas 2 magnitudes mais brilhantes teria mais causado uma exposição excessiva dessas estrelas, cujas medições teriam sido prejudicadas por erros sistemáticos. Enfim, Eddington considerou que o ponto forte das poucas placas de Príncipe era que, com a ajuda das placas de verificação, elas tinham passado pelo teste dos erros sistemáticos. As placas de Sobral nem tinham placas de verificação.

Outro ponto favorável às placas de Príncipe é que lá não houve o efeito nocivo dos raios solares no espelho, pois o véu de nebulosidade tinha atenuado a fulgurância do Sol. De fato, as condições climáticas em Príncipe no eclipse teriam sido verdadeiramente excepcionais, tanto que foram consideradas altamente improváveis em futuros eclipses. A temperatura ambiente se manteve incrivelmente uniforme, não variando além de $4^{\circ}$ durante toda a visita, incluindo

103 DYSON, F. W., EDDINGTON, A. S. and DAVIDSON, C. Ibid., 1920, p. 312.

104 Eddington considerou que os erros relevantes das medidas não eram aqueles que se distribuem aleatoriamente em torno de uma média, mas os que deslocavam sistematicamente a média para um valor menor. 
dia e noite, estação quente e chuvosa ou seca e fria. Durante o eclipse não houve queda perceptível de temperatura antes da totalidade.

Assim, culpando a má qualidade das imagens, mas sem fazer menção ao fato de que nem sequer puderam ser submetidas ao teste de placas de verificação, as placas do astrógrafo de Sobral foram descartadas.

De Sobral, sobraram então 7 placas obtidas com o telescópio de 4 polegadas. Suas medições se atrasaram pela necessidade de se adaptar o micrômetro para portar placas que tinham um tamanho não usual. De antemão ninguém duvidava que a decisão final repousava nessas placas, uma vez que as imagens eram quase ideais e ainda tinham escala maior que a de outras placas. O manejo do telescópio de 4 polegadas tinha imposto aos observadores grandes dificuldades: o comprimento desajeitadamente grande do telescópio que tinha um foco de 19 pés $(5,8 \mathrm{~m})$, o tempo de exposição mais longo exigido pelo tamanho menor da objetiva $(10 \mathrm{~cm})$, o que exigia do mecanismo de relojoaria um rastreio mais preciso e a escala de placa maior que tornava o foco mais crítico a vibrações. Não obstante, os observadores em Sobral obtiveram imagens que superaram todas as expectativas.

Usando a placa de escala, os desvios $\Delta x$ e $\Delta y$ foram medidos para cada uma das 8 estrelas selecionadas em todas as 7 placas do eclipse. Assim foi possível eliminar fisicamente o erro de escala das placas do eclipse, sem que o seu valor precisasse ser determinado. Em seguida, da média da deflexão da luz obtida do conjunto das placas do eclipse se subtraiu a média da deflexão obtida do conjunto das placas de comparação e se obteve a deflexão para o limbo solar que, corrigida em seguida para a refração diferencial e aberração, forneceu o valor final da deflexão no limbo de 1,98" com erro provável de \pm 0,12" (DYSON, EDDINGTON and DAVIDSON, 1920, p. 328) ${ }^{105}$. A possibilidade de erro sistemático foi afastada após constatar um padrão satisfatório de similaridade entre as imagens estelares das placas do eclipse e das placas de comparação. Saiu então o veredito final confirmando a deflexão de Einstein. No fim Eddington disse que o melhor teste de aprovação dessas placas foi a notável concordância interna entre as medidas de diferentes estrelas.

DYSON, EDDINGTON and DAVIDSON (1920, p. 331) ${ }^{106}$ tiraram suas conclusões sem negar maior peso estatístico à deflexão de 1,98 " $\pm 0,12$ ” obtida com as placas de Sobral107

\footnotetext{
105 DYSON, F. W., EDDINGTON, A. S. and DAVIDSON, C. Ibid., 1920, p. 328.

106 DYSON, F. W., EDDINGTON, A. S. and DAVIDSON, C. Ibid., 1920, p. 331.

107 Ao pé da letra essa conclusão sustenta que as placas de Sobral obtidas com o telescópio de 4 polegadas, em conjunto com as placas do astrógrafo utilizado em Príncipe, ajudaram a confirmar a predição de Einstein. Se o peso estatístico das placas de Sobral era maior, isso foi diminuído porque para Eddington, os erros dominantes não eram aleatórios, mas sistemáticos.
} 
feitas com o telescópio de 4 polegadas, principalmente porque as imagens tinham melhor qualidade, o erro provável era menor e a escala da fotografia era maior. Mas Eddington nunca deixou de levar em consideração as duas placas de Príncipe obtidas com o astrógrafo para corroborar a predição de Einstein. Ele, assim, pôde apresentar dois resultados congruentes obtidos com diferentes instrumentos, em diferentes lugares e com diferentes análises. É admirável como Eddington transformava a falta de homogeneidade no tratamento dos dados, algo que seria uma falha, numa virtude (EDDINGTON, 1920, p. 108) ${ }^{108}$.

Em resumo, sendo 1,74" a predição einsteiniana da deflexão, os resultados finais para o bordo do disco solar, acompanhados dos erros prováveis foram para Sobral: 1,98" $\pm 0,12$ " e para Principe: $1,61 " \pm 0,30 ”$.

Considerando que a deflexão decai linearmente tanto na previsão de Einstein como na teoria de Newton, foram tomados os valores médios da deflexão de 7 estrelas das placas de Sobral com o telescópio de 4 polegadas. Esses valores foram colocados num gráfico (DYSON, EDDINGTON and DAVIDSON, 1920, p. 332) ${ }^{109}$ que mostra o deslocamento radial (") versus distância radial ('). A curva resultante foi comparada ao decaimento radial da deflexão einsteiniana e da deflexão newtoniana. Essa análise se mostrou conveniente para argumentar, não tanto o valor preciso da amplitude da deflexão, mas para mostrar que a amplitude da deflexão einsteiniana era decididamente maior que a da deflexão newtoniana. Logo no início do artigo era declarado que o objetivo da observação do eclipse de 1919 era discriminar qual seria o resultado dentre as três alternativas: 1) deflexão nula: nenhum efeito gravitacional na luz; 2) deflexão total de 1,74" predita pela teoria einsteiniana e 3) metade dessa deflexão predita pela teoria de Newton (DYSON, EDDINGTON and DAVIDSON, 1920, p. 291) ${ }^{110}$.

A conclusão do artigo termina menos peremptoriamente do que começa, ao sugerir um tanto quanto incoerentemente que novas observações sejam feitas:

\begin{abstract}
the results of the expeditions to Sobral and Principe can leave little doubt that a deflection of light takes place in the neighbourbood of the sun and that it is of the amount demanded by Einstein's generalised theory of relativity, as attributable to the sun's gravitational field. But the observation is of such interest that it will probably be considered desirable to repeat it at future eclipses (DYSON, EDDINGTON and DAVIDSON, 1920, p. 332) $)^{111}$.
\end{abstract}

Os autores recomendaram ainda evitar no futuro o uso do celóstato cujo espelho, ao refletir a luz solar deteriora a imagem. Para dispensar o espelho recomendaram acomodar o

\footnotetext{
108 EDDINGTON, Arthur S. Ibid., 1920, p. 108.

${ }^{109}$ DYSON, F. W., EDDINGTON, A. S. and DAVIDSON, C. Ibid., 1920, p. 332.

${ }^{110}$ DYSON, F. W., EDDINGTON, A. S. and DAVIDSON, C. Ibid., 1920, p. 291.

111 DYSON, F. W., EDDINGTON, A. S. and DAVIDSON, C. Ibid., 1920, p. 332.
} 
telescópio em montagem equatorial, que é capaz de manter a objetiva do telescópio continua e diretamente apontada para o Sol.

\section{Comunicação do resultado}

\section{Apresentações preparatórias}

Vimos que ainda em Príncipe Eddington já tinha pressentido que a deflexão einsteiniana seria confirmada, não a newtoniana. Na volta para a Inglaterra ele transmitiu para Dyson um telegrama falando disso. Eddington desembarcaria em Liverpool no dia 14/7/1919.

Poucos dias antes, em 11/7/1919 Campbell estava de passagem por Londres ${ }^{112}$ e foi convidado para fazer uma comunicação na RAS (FOWLER, 1919, pp. 298-299) ${ }^{113}$ sobre a Expedição Crocker do Observatório de Lick ao eclipse solar de 2/6/1918 em Goldendale (CAMPBELL, 1918) ${ }^{114}$, para observar a deflexão da luz a pedido de Eddington. A comunicação era de caráter preliminar e Campbell falou que não pôde utilizar os instrumentos que tinha levado para a Rússia em 1914, pois ficaram lá retidos por anos. Então foram utilizadas duas objetivas fotográficas emprestadas, de 4 polegadas. Foram feitas várias placas que continham cerca de 50 estrelas, sendo de magnitude 9 as de brilho mais fraco. Placas de comparação do campo estelar do eclipse foram feitas 7 meses depois do eclipse. Curtis estava encarregado da análise dessas placas, mas ele ainda não tinha completado o trabalho. Campbell adiantou que não havia sido descoberto nenhum deslocamento sistemático de estrelas segundo a predição de Einstein. Uma análise de placas de eclipses antigos também havia sido feita por Curtis, e Campbell era de opinião de que os resultados excluíam a possibilidade da deflexão maior (einsteiniana), mas não da menor (newtoniana).

Na sequência da sessão da RAS, o Astrônomo Real (Dyson) deu notícia dos primeiros resultados promissores da análise feita por Eddington ainda na expedição, recebidos dois dias antes. Assim, duas notícias conflitantes chegaram ao mesmo tempo. Impressiona que o anúncio do resultado positivo de Eddington foi feito como se Campbell não tivesse feito a sua comunicação, e isso é mais impressionante porque Campbell tinha feito a observação a pedido expresso de Eddington. Para Campbell, pessoa eticamente estrita, essa ocorrência amplificou sua preocupação em relação à adequação dos instrumentos utilizados na observação, assim como em relação às medições feitas por Curtis. Este episódio nos convida a uma digressão para fazer jus ao

112 O destino principal da viagem de Campbell era Bruxelas onde ele representaria os Estados Unidos numa reunião do International Research Council. Essa reunião era importante no contexto do antigermanismo dos cientistas das Potências Aliadas da I Guerra.

113 FOWLER, A. (Chairman). Meeting of the Royal Astronomical Society, Friday, 1919 July 11, The Observatory, v. 42, n. 542, 297-306, 1919, pp. 298-299.

114 CAMPBELL, W. W. The Crocker Eclipse Expedition from the Lick Observatory, University of California, June 8, 1918, Publications of the Astronomical Society of the Pacific, v. 30, n. 176, 1918, 219-240. 
admirável comprometimento ético-profissional de Campbell, que sofria pressão de Curtis que rejeitava a Relatividade.

Curtis fazia as medições das placas do eclipse para Campbell e, sendo um anti-relativista convicto e renitente, desejava e estava ansioso para publicar os resultados negativos que tinha obtido das placas de Goldendale. Porém, ele deixou Lick em julho de 1920 para se tornar diretor do Observatório Allegheny, da Universidade de Pitsburgo, PA, deixando Campbell livre para exercitar sua vontade de não publicar o resultado. Mas em setembro de 1920, Campbell retomou ele próprio a medição das placas do eclipse e concluiu que as placas de comparação eram de má qualidade. Considerou então que o problema estava na montagem improvisada que foi utilizada. Por isso, em outubro instalou as lentes na montagem sólida do grande refletor de Lick e tentou obter melhores placas. Mesmo assim as imagens resultantes estavam superexpostas e com rastros. Em dezembro Campbell escreveu para Curtis opinando que as lentes não tinham qualidade para responder à questão da deflexão da luz. Preocupado em preservar a reputação do Observatório de Lick, Campbell quis então publicar uma nota apenas afirmando que os resultados não decidiam a favor, nem contra o efeito da deflexão, relembrando as improvisações que teve que fazer na véspera do eclipse no telescópio, na montagem e no mecanismo de relojoaria por causa da retenção dos instrumentos na Rússia. Campbell estava disposto a descartar um ano de seu trabalho, mas Curtis não gostou dessa ideia. Em 29/12/1920 mandou uma resposta (EARMAN and GLYMOUR, 1980a, 65-66) ${ }^{115}$, inclusive com um rascunho de texto para publicação, que não deixasse de incluir as medidas obtidas. Eis um trecho:

The mean of the above results suggests the gravitational deflection of 0.87 at the Sun's limb. From the data given earlier as to the character of the plates employed, from the probable errors of the separate plates, and from the serious lack of agreement in the individual results, we do not believe that these results permit a decision for or against the Einstein or other deflection bypothesis, and these indecisive results are published simply as a matter of record.

Dirigindo-se a Campbell disse:

\begin{abstract}
A simple, frank statement, as above, of indecisive results secured will, so far from burting the L. O. [Lick Observatory], increase its already great reputation for sanity and conservatism, and for not announcing theories till it can deliver the goods. When the Einstein theory goes into the discard, as I prophesy it will go within ten years, these negative or indecisive results will be more bighly regarded than at present.
\end{abstract}

Embora Campbell quisesse ter esta discussão encerrada no final de 1920, até maio de 1921 ele continuou analisando os dados, fazendo novas imagens de comparação evitando superexposição. Em 19/5/1921 voltou a escrever para Curtis dizendo que em breve completaria o trabalho, mas aproveitou para consultá-lo sobre qual seria a causa de estranhos movimentos das câmeras no eclipse de Goldendale, que produziram uma imagem de forma estranha assumida

${ }^{115}$ EARMAN, J. and GLYMOUR, C. Ibid., 1980a, pp. 65-66. 
pelas estrelas que se encontravam onde o foco era melhor. Curtis opinou que a falha deveria estar na falta de rigidez da montagem de madeira e dos tubos. Mas Campbell não enviou a Curtis nem os resultados de suas últimas medições, nem o relatório que, se foi escrito, nunca foi publicado.

Mesmo após os resultados obtidos pela expedição de Lick no eclipse de 1922, desta vez de acordo com a predição de Einstein, Curtis disse numa carta que não estava disposto a engolir a teoria de Einstein, se é que isso aconteceria algum dia, e se declarou herege (EARMAN and GLYMOUR, 1980a, p. 68) ${ }^{116}$. O eclipse de 1918 acabou não produzindo nunca nenhum resultado que chegasse a ser publicado. Mas as repetidas medições das placas desse eclipse, os repetidos cálculos da deflexão e das fontes de erro tiveram um valor inestimável, pois deram para Campbell e sua equipe uma sólida bagagem para a medição da deflexão da luz no eclipse de 1922. Durante algum tempo essas medidas constituíram o mais firme respaldo para a deflexão einsteiniana da luz.

Voltemos agora à comunicação da confirmação da predição de Einstein com base na análise das placas do eclipse de 1919. A partir de julho daquele ano, ou seja, desde que retornou de Príncipe, Eddington começou a fazer apresentações dos resultados preliminares do eclipse de 1919 tanto para especialistas profissionais como também para o público leigo. Inicialmente eram apresentados só os resultados preliminares de Príncipe porque os de Sobral ainda não estavam disponíveis. Uma dessas apresentações foi em 12/9/1919 na British Association for the Advancement of Science. Nela Eddington se limitou a dizer que suas medições iniciais sugeriam uma deflexão intermediária entre a total predita por Einstein e a metade dela predita pela teoria de Newton, e que esperava que a análise completa favorecesse o valor de Einstein (ALMASSI, 2009, p. 61) ${ }^{117}$. $\mathrm{Na}$ audiência estava o físico relativista polonês, Ludwik Silberstein (1872-1948), autor de um livro texto de 1914 sobre Relatividade Restrita ${ }^{118}$ e que escreveria um outro em 1922 sobre a Relatividade Geral (SILBERSTEIN, 1922) ${ }^{119}$. Silberstein lembrou que a não confirmação experimental do deslocamento gravitacional das linhas espectrais para o vermelho (outra predição de Einstein) era problemática para a Relatividade Geral. Silberstein se referia às observações do astrônomo americano Charles E. St. John (1875-1935) do Observatório de Monte Wilson, então autoridade em linhas espectrais do Sol, que havia tentado detectar, sem sucesso, o deslocamento espectral para o vermelho entre 1915 e 1919 (EARMAN and GLYMOUR, 1980b) ${ }^{120}$. Também o nosso já conhecido padre Cortie, presente na reunião relembrou que, segundo a comunicação de Campbell na reunião de 11/7/1919 na RAS, as fotografias do eclipse de 1918 não tinham

116 EARMAN, J. and GLYMOUR, C. Ibid. 1980a, p. 68.

117 ALMASSI, Ben, Ibid., 2009, p. 61.

118 SILBERSTEIN, L. The Theory of Relativity. London: McMillan \& Co. Ltd., 1914.

119 SILBERSTEIN, Ludwik. The Theory of General Relativity and Gravitation. New York: D. Van Nostrand Co., 1922.

120 EARMAN, John and GLYMOUR, Clark. The Gravitational Red Shift as a Test of General Relativity: History and Analysis. Studies in History and Philosopby of Science, v. 2, n. 3, 175-214, 1980 b. 
evidenciado a deflexão da luz. Portanto as declarações de Eddington não eram recebidas unânime e pacificamente. Havia autorizadas vozes dissonantes.

O fato de as objeções, desde o início, ficarem quase despercebidas, apesar de os resultados observacionais deixarem alguma dúvida residual, foi explicada pelo historiador da ciência moderna da Universidade Vanderbilt, TN, Alistair Sponsel, pela prolífica comunicação de Eddington através de palestras empolgantes e publicações em diferentes revistas que estavam fazendo a mensagem atingir o alvo certo (SPONSEL, 2002, p. 454) ${ }^{121}$. Desde agosto de 1919 até a famosa reunião conjunta de 6 de novembro daquele ano, em que a comprovação da deflexão einsteiniana foi anunciada ao grande público, Eddington e Dyson fizeram uma campanha de relações públicas para preparar a Grã-Bretanha para bem receber o anúncio da Revolution in Science. É admirável a precocidade com que Eddington e Dyson se deram conta da importância da comunicação social para a ciência. Para Sponsel, que abordou a questão do ponto de vista do papel da comunicação social na Sociologia do Conhecimento Científico (Sociology of Scientific Knowledge - SSK), essa campanha publicitária cuidadosamente articulada para cultivar expectativas em torno do eclipse de 1919 e promover uma recepção favorável dos resultados, explica por que a maioria dos cientistas e do grande público logo concedeu credibilidade aos resultados anunciados, obtidos já na primeira tentativa de uma observação sabidamente difícil e desafiadora (SPONSEL, 2002, p. 440-441) ${ }^{122}$. A comunicação também alcançou êxito, a meu ver, devido à autoridade acadêmica de seus promotores.

Ben Almassi, aqui já citado pesquisador em Filosofia da Ciência e Filosofia Aplicada da Governors State University em University Park, IL, analisou o anúncio da confirmação do efeito Einstein na confluência da "epistemologia social" com a ética prática dos "especialistas" e defendeu que não houve da parte dos pares aceitação cega dos resultados do eclipse de 1919 mas que, no contexto de um vácuo epistemológico, no que dizia respeito à Relatividade Geral, os pares que pouco entendiam desse assunto e das suas implicações observacionais na deflexão da luz, confiaram no testemunho do maior especialista na época entre eles, o próprio Eddington. No tocante à análise dos dados, havia vários astrônomos e físicos competentes que tinham conhecimento de causa, mas estes não fizeram objeção (ALMASSI, 2009) ${ }^{123}$. Com base no que expus anteriormente, tenho dificuldade em concordar com essa interpretação e acredito que havia pares competentes, não só em análise de dados astronômicos como também em Relatividade. A campanha publicitária bem orquestrada por Eddington e Dyson, contando com o importante apoio dado pelos dirigentes de sociedades e comissões científicas (inclua-se aí a JPEC) e com

121 SPONSEL, Alistair. Constructing a 'Revolution in Science': The Campaign to Promote a Favourable Reception for the 1919 Solar Eclipse Experiments. The British Journal for the History of Science, v. 35, n. 4, 439467, 2002, p. 454.

122 SPONSEL, Alistair. Ibid., 2002, p. 440-441.

123 ALMASSI, Ben. Ibid., 2009. 
bons canais da grande mídia, ocupou hegemonicamente todos os espaços e, muito provavelmente, mesmo os especialistas em análise de dados que poderiam formular críticas objetivas, talvez nunca tivessem tido acesso aos dados brutos, como também poderiam ter se intimidado por já saberem das estressantes controvérsias que Eddington nunca poupava.

Almassi recolheu importantes detalhes documentais que ajudam a esclarecer como foi essa campanha de relações públicas. Eddington dirigiu discussões sobre a Relatividade e deu palestras sobre a expedição do eclipse de 1919 para diversos públicos populares ou profissionais. Almassi se concentrou no encontro de 22/10/1919 no $\nabla^{2} V^{124}$ Club em Cambridge. Nele Eddington apresentou os resultados do eclipse de 1919 e Dyson, em seguida, agendou a importante reunião conjunta da RS e RAS para duas semanas depois. Considera-se que esse encontro do $\nabla^{2} V$ Club, embora de caráter informal, consolidou suficiente confiança em Eddington e Dyson para que este, Astrônomo Real e com poder de tomar essa decisão, anunciasse a reunião conjunta. Desde a fundação em 1899 até 1916 as reuniões eram feitas a cada poucos meses, mas a I Guerra tinha imposto um longo hiato. Assim Eddington e Dyson estavam rompendo essa interrupção. Os registros da reunião são superficiais e incompletos, mas dá a lista dos membros presentes e diz que Eddington

spoke on the topic of the weight of light as concerned his May expedition. He is reported to have presented the underlying theory, experimental setup, data analysis, and a mean deflection of 1,60" at Principe; a Sobral deflection value was alluded to indirectly as roughly 1,75" with a six percent probable error. Eddington characterized the presented results as confirming Einstein's theory. The meeting was not declared social until after midnight [which suggests that there was much critical discussion], at which point club president Ebenezer Cunningham declared that the meeting had been an historic occasion and joked that after Eddington's presentation the name of the club would perhaps need to be changed to something more "barbaric" (ALMASSI, 2009, p. 63)125.

O foco do $\nabla^{2} V$ Club era a Física Matemática e novos membros eram admitidos quando apresentados por um membro e aprovado pela maioria absoluta dos membros, o que ajudava a manter o foco. Os membros eram físicos, astrônomos e matemáticos da área da Matemática Aplicada. Já os membros da RS eram escolhidos a partir de diferentes especializações. Assim, embora a reunião conjunta de 6 de novembro, por ser mais formal, tenha se tornado mais conhecida, muitos dos membros da RS ali presentes estavam menos aptos para julgar o trabalho de Eddington por eles próprios. O próprio Almassi não deve ter exagerado nessa consideração. Isso significa que na reunião conjunta as barreiras críticas eram mais transponíveis do que no encontro do $\nabla^{2} V$ Club. Na reunião conjunta que veremos em seguida, estavam muitos membros profissionalmente capacitados para entender e julgar criticamente a apresentação, contudo a audiência do $\nabla^{2} V$ Club was considerably denser with relevant experts (ALMASSI, 2009, p. 64) ${ }^{126}$. Almassi

124 Aqui o símbolo do operador matemático chamado laplaciano aplicado ao potencial gravitational, iconiza a Mecânica Clássica ou de Newton.

125 ALMASSI, Ben. Ibid., 2009, p. 63.

126 ALMASSI, Ben. Ibid., 2009, p. 64. 
considera que na reunião do $\nabla^{2} V$ Club, profissionais competentes em Relatividade e em astronomia observacional conferiram, embora informal e não unanimemente, credibilidade ao anúncio que seria feito depois na reunião conjunta.

Perante a JPEC, demostrando uma confiança desproporcionalmente audaciosa nos resultados obtidos, Dyson declarou: after a careful study of the plates I am prepared to say that there can be no doubt that they confirm Einstein's prediction. A very definite result has been obtained that light is deflected in accordance with Einstein's law of gravitation.

Em seguida Eddington declarou:

\begin{abstract}
for the full effect which has been obtained we must assume that gravity obeys the new law proposed by Einstein. This is one of the most crucial tests between Newton's law and the proposed new law. This effect may be taken as proving Einstein's law rather than his theory. It is not affected by the failure to detect the displacement of Fraunbofer lines on the Sun. If this latter failure is confirmed it will not affect Einstein's law of gravitation, but it will affect the views on which the law was arrived at. The law is right, though the fundamental ideas underlying it may yet be questioned (SPONSEL, 2002, p. 461$)^{127}$.
\end{abstract}

A deflexão estava confirmada, mas uma porta ficava entreaberta para que a Relatividade Geral pudesse eventualmente ser questionada, ou seja, a deflexão poderia não ser parte integrante do edifício teórico da Relatividade Geral.

\title{
Sessão conjunta de 6/11/1919
}

As sessões conjuntas eram excepcionais e vinham sendo realizadas com o propósito expresso de anunciar os resultados de observações de eclipses (SPONSEL, 2002, p. 455) ${ }^{128}$. Na sessão conjunta que, segundo estimativa de SPONSEL (2002, p. 460) ${ }^{129}$ teria reunido de 100 a 150 participantes, os resultados do eclipse de 1919 foram apresentados por Eddington, Dyson e Crommelin. Segundo EARMAN e GLYMOUR (1980a, pp. 76-77) ${ }^{130}$, a sessão foi presidida pelo Presidente da RS, Sir Joseph Thomson (1856-1940), o descobridor do elétron e Nobel de Física de 1906. Ele convidou o Astrônomo Real, Dyson, para apresentar os resultados de Sobral, o que ele fez novamente com muita firmeza:

The astrographic plates gave 0.97" for the displacement at the limb when the scale-value was determined from the plates themselves, and 1.40" when the scale-value was assumed from the check-plates ${ }^{131}$. But the much better plates [4 inch] gave for the displacement

127 SPONSEL, Alistair. Ibid., 2002, p. 461.

128 SPONSEL, Alistair. Ibid., 2002, p. 455.

129 SPONSEL, Alistair. Ibid., 2002, p. 460.

${ }^{130}$ EARMAN, J. and GLYMOUR, C. Ibid., 1980a, 76-77.

131 A menção a check-plates para placas de Sobral obtidas com o astrógrafo nos confunde porque check-plates foram preparadas só para Príncipe. Por outro lado, se a correção de escala obtida com check-plates preparadas para Príncipe foi usada para Sobral, isso não faz muito sentido porque a óptica do astrógrafo usado em 
at the limb 1.98", Einstein's predicted value being 1.75". Further, for these plates the agreement between individual stars was all that could be expected. (EARMAN and GLYMOUR, 1980a, pp. 76-77) ${ }^{132}$.

Depois foi a vez de Eddington falar sobre os resultados de Príncipe:

Of the 16 plates taken during the five minutes of totality the first 10 showed no stars at all; of the later plates two showed five stars each, from which a result could be obtained. Comparing them with the check-plates secured at Oxford before we went out, we obtained as the final result from the two plates for the value of the displacement at the limb 1.6" $\pm 0.3 "$. The p.e. [probable error] was determined from the residuals of individual stars. This result supports the figures obtained at Sobral (EARMAN and GLYMOUR, 1980a, p. 77) ${ }^{133}$.

Segundo Earman e Glymour, a discussão que veio em seguida evidencia o peso da autoridade (ou superautoridade) de Eddington e Dyson. Thomson disse: It is difficult for the andience to weigh fully the meaning of the figures that have been put before us, but the Astronomer Royal and Prof. Eddington have studied the material carefully, and they regard the evidence as decisively in favor of the larger value for the displacement. Assim Thomson endossou os resultados e a Relatividade Geral dizendo: This result is not an isolated one, it is a whole continent of scientific ideas... This is the most important result obtained in connection with the theory of gravitation since Newton's day, and it is fitting that it should be announced at a meeting of the Society so closely connected with him.

A meu ver isso põe em evidência que a análise dos dados, indubitavelmente ponto focal da discussão, nem chegou a ser revisada por aqueles que tinham competência para fazer isso. EARMAN e GLYMOUR (1980a, p. 78-79)134 disseram que não aparecem nos registros da sessão questionamentos sobre a determinação do erro provável das medidas de Sobral com o telescópio de 4 polegadas, nem sobre a justificação ao peso dado aos resultados de Príncipe e nem sobre o peso nulo atribuído às placas astrográficas de Sobral. Esta mesma questão foi colocada também por Campbell, ainda que tardiamente em 1923: Professor Eddington was inclined to assign considerable weight to the African determination, but, as the few images on his small number of astrographic plates were not so good as those on the astrographic plates secured in Brazil, and the results from the latter were given almost negligible weight, the logic of the situation does not seem entirely clear (CAMPBELL, 1923, p. 19) ${ }^{135}$. Este depoimento revela que Campbell não se deixara convencer pela argumentação de Eddington.

Sobral não é a mesma do astrógrafo de Greenwich usado em Príncipe. A inclusão do novo valor da deflexão de 1,40" talvez tivesse sido motivada por se aproximar mais da predição einsteiniana e ela reaparece, com valor numérico um pouco alterado (1,56”) em DYSON, 1921, nota de rodapé 138.

132 EARMAN, J. and GLYMOUR, C. Ibid., 1980a, p. 76-77.

133 EARMAN, J. and GLYMOUR, C. Ibid., 1980a, p. 77.

${ }^{134}$ EARMAN, J. and GLYMOUR, C. Ibid., 1980a, p. 78-79.

135 CAMPBELL, W. W. The Total Eclipse of the Sun, September 21, 1922, Publications of the Astronomical Society of the Pacific, v. 35, 11-26, 1923, p. 19. Neste artigo Campbell recapitula a participação pioneira do Observatório de Lick na observação do efeito Einstein. 
A aprovação aparentemente imediata e unânime dos resultados na reunião conjunta, também não teria sido como frequentemente se fez parecer. O astrônomo inglês Alfred Fowler (1868-1940), então Presidente da RAS, embora tenha se pronunciado favoravelmente na reunião conjunta, fez reservas por causa dos resultados negativos obtidos até então sobre o deslocamento gravitacional de linhas espectrais para o vermelho. Silberstein defendeu que os resultados do eclipse não confirmariam a Relatividade Geral enquanto perdurassem os resultados negativos das medidas desse efeito. A essa objeção Eddington teria respondido que os resultados do eclipse não confirmavam a Teoria da Relatividade Geral, mas apenas as equações de Einstein para a trajetória da luz num campo gravitacional, o que deve ter deixado Silberstein completamente insatisfeito (EARMAN and GLYMOUR, 1980a, p. 78) ${ }^{136}$. O físico e consultor científico do governo britânico, alemão de nascimento Frederick A. Lindemann (1886-1957) falou da possibilidade sugerida pelo astrofísico Hugh Newall (1857-1944), de interpretar os resultados como devidos à refração pela matéria coronal.

Segundo ALMASSI (2009, p. 65) ${ }^{137}$, após a sessão conjunta de 6/11/1919, outros concorridos encontros tratando do mesmo assunto foram promovidos, como a conferência pública em Cambridge de 11 de dezembro daquele ano, a reunião da RAS no dia seguinte, a reunião da RS de 5/2/1920 e a reunião da Physical Society de 26/3/1920. Nesses encontros a Relatividade foi discutida animadamente e defendida, ao menos em parte, por físicos e astrônomos como o matemático estatístico e astrônomo Harold Jeffreys (1891-1949) e o físico, matemático e astrônomo James H. Jeans (1877-1946), além obviamente de Eddington e Dyson, e dos já citados Cunningham e Lindemann. Mas havia também físicos e astrônomos de reputação comparável que faziam críticas como Oliver J. Lodge (1851-1940), pioneiro da rádio-comunicação e que ainda estava apegado à hipótese do éter luminífero e achava que a deflexão da luz era devida a uma maior densidade do éter nas proximidades do Sol. Lodge escreveu vários artigos e deu várias palestras defendendo sua hipótese que, na verdade, tinha sido proposta antes por Jonckhèere de quem falarei mais adiante. Mas a requerida densidade do éter para produzir a deflexão deveria ser tão elevada que deveria também diminuir o brilho das estrelas perto do Sol, o que não era observado. O já citado Silberstein, na reunião da RAS de 12/12/1919 argumentou que o fato de os deslocamentos estelares nas placas do telescópio de 4 polegadas de Sobral não serem uniformemente radiais, evidenciava que eles não eram causados pela gravidade, mas por alguma refração irregular da matéria solar. Disse ainda: If we had not the prejudice of Einstein's theory we should not say that the figures strongly indicated a radial law of displacement. O já citado Robert Jonckhèere (18881974), francês de família rica que chegou a ter um observatório particular em Lille, era outro crítico. Por causa da ocupação alemã em 1914, Jonckhèere se refugiou com seus filhos e mulher na Inglaterra, já que a esposa era inglesa. Durante a I Guerra ele obteve permissão de Dyson

136 EARMAN, J. and GLYMOUR, C. Ibid., 1980a, p. 78.

${ }^{137}$ ALMASSI, Ben. Ibid., 2009, p. 65. 
para fazer observações no Observatório Real de Greenwich e, assim, Jockhèere se tornou um famoso descobridor de estrelas duplas. Em relação à deflexão da luz ele achava que era causada, se não pelo éter, então pela atmosfera solar. Mas, então, a estabilidade de tal atmosfera deveria ser controlada pela gravidade solar e, nesse caso, a densidade seria proibitivamente elevada. Nem mesmo uma força de origem elétrica ou a pressão de radiação removeria essa dificuldade. Além disso, a refração que ocorreria em consequência seria observada nos cometas rasantes ao Sol, o que não acontecia. Nem o movimento desses cometas, que seria retardado por atmosfera tão densa, era observado.

Surgiu também a ideia de que o resfriamento rápido da atmosfera superior da Terra durante a passagem da sombra da Lua deveria dar lugar a uma brusca diferença de temperatura entre a parte resfriada e a parte não resfriada, de modo a causar a mudança aparente de posição das estrelas sem necessariamente envolver a Relatividade. Eddington respondeu que esse efeito seria mínimo, da ordem de 1/20 do efeito predito por Einstein. Essa objeção acabou sendo retirada pelo próprio proponente. Em 1921 Dyson respondeu a algumas dessas objeções (DYSON, 1921) ${ }^{138}$.

ALMASSI (2009, p. 64) ${ }^{139}$ confirma que nos registros dessas reuniões there is no recorded criticism of Eddington's data-analytical methodology. Ele considerou significativo que os físicos e astrônomos britânicos não criticaram a análise dos dados e que, em vez disso, propuseram outras explicações para a deflexão da luz (ALMASSI, 2009, p. 58) ${ }^{140}$, o que atestaria que os colegas de profissão, aptos a julgarem a análise dos dados, não a teriam reprovado. Mas minha conjectura é a de que, a falta de escrutínio nos dados e na sua análise, que teria sido determinante para os rumos dos acontecimentos, ocorreu porque os pares capacitados a fazer a revisão crítica foram sufocados pela avassaladora campanha publicitária e pela força do "argumento de autoridade" de Eddington.

Apesar da persistente falta de unanimidade, a confirmação da deflexão e da Relatividade Geral foi anunciada e propalada ao grande público pela imprensa. Resultado: instantaneamente Einstein que, até então era um cientista obscuro para o grande público, conhecido e respeitado apenas na pequena comunidade europeia, se tornaria um gênio e cientista mundialmente renomado. Ironicamente a maioria antigermânica da comunidade científica dos Países Aliados assistiu à teoria de um judeu, que trabalhava em Berlim, sendo confirmada por um quacre inglês. Mas isso era exatamente o que Eddington desejava desde o início, a fim de forçar os cientistas compatriotas a uma atitude mais aberta e generosa em relação aos colegas alemães (EARMAN and

138 DYSON, Sir Frank, Relativity and the Eclipse Observations of May, 1919, Nature, v. 106, n. 2677, 786787, 1921.

139 ALMASSI, Ben. Ibid., 2009, p. 64.

140 ALMASSI, Ben. Ibid., 2009, p. 58. 
GLYMOUR, 1980a, p. 85) ${ }^{141}$. Em 1933 numa conversa em volta da lareira, o físico considerado pai da Física Nuclear, Ernest Rutherford (1871-1937) teria dito a Eddington: You made Einstein famous (CHANDRASEKHAR, 1983, p. 28) ${ }^{142}$.

\section{Boas e más repercussões da "Revolution in Science"}

A sessão conjunta foi imortalizada pelo famoso matemático e filósofo inglês Alfred N. Whitehead (1861-1947) em duas passagens: a great adventure in thought [Relatividade Geral] had at length come safe to shore e to remind us that the greatest of scientific generalisations [Teoria Gravitacional de Newton] was now after more than two centuries, to receive its first modifications (WHITEHEAD, 1925, p. $16)^{143}$.

Segundo a grande imprensa, certamente receptiva às declarações de figurões como Thomson e Whitehead, as observações tinham confirmado de forma definitiva a deflexão einsteiniana da luz, mas não a newtoniana. De tabela, o anúncio proclamava também a solidez da Teoria da Relatividade Geral e a derrocada da teoria de Newton. O jornal londrino The Times, de 7 de novembro publicou a seguinte manchete: Revolution in Science. New Theory of the Universe. Newtonian Ideas Overthrown. Momentous Pronouncement. Space 'Warped'.

Mas essa manchete não veio do nada. Era a culminação de uma campanha programada que já vinha tratando do eclipse de 1919 por esse jornal há 10 meses. Qualquer leitor assíduo do The Times já estava bem informado do objetivo e implicação da expedição e estava preparado e ansioso para receber o anúncio da confirmação de que as ideias de Newton tinham sido destronadas (SPONSEL, 2002, p. 444) ${ }^{144}$. Dias depois, o New York Times publicou a manchete: Lights all askew in the heavens/Men of Science more or less agog over results of eclipse observations/Einstein theory triumphs.

Há uma visível diferença, nem sempre sublinhada, entre o discurso ainda cauteloso de Eddington e as manchetes pomposas e taxativas da imprensa mundial. Apesar da retórica otimista, Eddington e seus colegas tinham recomendado novas medições confirmatórias, o que seria desnecessário se a deflexão da luz tivesse sido definitivamente confirmada. Eles também, quando pressionados, se limitaram a confirmar a predição da deflexão da luz, mas não necessariamente a Teoria da Relatividade Geral. Portanto é estranho que nem Eddington, nem Dyson tenham reclamado do otimismo exagerado da mídia.

${ }^{141}$ EARMAN, J. and GLYMOUR, C. Ibid., 1980a, p. 85.

142 CHANDRASEKHAR, S. Ibid., 1983, p. 28.

143 WHITEHEAD, Alfred N. Science and the Modern World. New York: Macmillan, 1925, p. 16.

144 SPONSEL, Alistair. Ibid., 2002, p. 444. 
Uma crítica mais recente foi feita à validação ipso facto da Relatividade Geral, como consequência lógica da confirmação do efeito Einstein, pois a dedução da deflexão feita por Einstein em 1916 seria problemática: What is more surprising is that the derivation of the deflection that Einstein gave in 1916, on the basis of the completed general theory, is almost as contrary to the spirit of the theory (EARMAN and GLYMOUR, 1980a, p. 54) ${ }^{145}$. O Princípio de Huygens é aplicado de forma inapropriada porquanto esse princípio depende da variação ponto a ponto da velocidade da luz, ao passo que na Relatividade Geral a velocidade da luz é invariante. O tratamento correto é pela integração das geodésicas nulas, em que o tempo é nulo na separação de dois eventos no espaçotempo e, portanto, essa integração representa o caminho mais curto para a luz (não para partícula dotada de massa). Nesse sentido a medição feita por Eddington, da deflexão predita por Einstein, confirmou apenas o valor predito, mas não a Relatividade Geral.

Mas a percepção do grande público era a de que a Relatividade Geral tinha sido confirmada de forma inquestionável. A palavra Relatividade estava em todas as bocas, o que não significava que as pessoas sabiam exatamente do que estavam falando. Um artigo do New York Times comentando as publicações do The Times, de Londres, dizia que o grande público admirava Einstein sem o compreender ou, talvez, o admirasse exatamente porque não o compreendesse. Mas, apesar da pouca compreensão da teoria científica, houve um forte impacto emocional.

A Relatividade mudou a nossa compreensão de senso comum do mundo em que vivemos, pois, a afirmação de que a velocidade da luz é constante, que estranhamente ela não depende da velocidade da fonte luminosa em relação a nós, de que o tempo, espaço e massa agora eram relativos ao movimento das coisas e a trajetória da luz podia ser curva no espaço, subverteu a percepção da nossa presença no mundo. O tecido do Universo havia mudado, uma questão científica, mas também filosófica e existencial. De uma forma ou de outra, a Relatividade considerada de difícil compreensão para o cidadão comum e, talvez, por isso, tão atraente e sedutora, acabou afetando também as artes e as ciências humanas, tendo redefinido a Física como estudo não dos eventos em si, mas das relações entre o observador e os eventos, introduzindo agora o sujeito na análise das coisas.

Segundo Sponsel, a imprensa americana foi o instrumento que fez de Einstein uma celebridade (SPONSEL, 2002, p. 443) ${ }^{146}$. Essa publicidade catapultou Einstein para a fama mundial e ele foi o primeiro cientista a ser homenageado em Nova Iorque, na Broadway, com desfile de papel picado. Conhecido e admirado agora na comunidade internacional, convites começaram a chover sobre ele para dar conferências no mundo todo. Em 1921 ele iniciou a primeira de uma série de turnês quando visitou os Estados Unidos, a Inglaterra, o Japão e a França. Onde quer que ele fosse, milhares de pessoas se juntavam. Nesse mesmo ano recebeu o Prêmio Nobel de

145 EARMAN, J. and GLYMOUR, C. Ibid., 1980a, p. 54.

146 SPONSEL, Alistair. Ibid., 2002, p. 443. 
Física, não pela teoria da Relatividade, mas pelos estudos sobre o efeito fotoelétrico. Até hoje sua fama permanece viva. No último número da revista americana Time do milênio passado (31/12/1999) ele foi declarado personalidade do século 20. Contudo, no curto prazo, sua fama e o sucesso de sua teoria trouxeram também repercussões negativas.

Nos meios científicos dos países anglófonos a recepção da Relatividade Restrita tinha sido quase uniformemente hostil e desdenhosa. Mormente os físicos ingleses tinham, em geral, aderido à mecânica do éter luminífero - algo muito afastado da Relatividade (EARMAN and GLYMOUR, 1980a, 50) ${ }^{147}$. A Relatividade Geral era a complementação ainda mal conhecida de uma teoria importada, mas já malvista. Eddington, portanto, foi uma exceção que rapidamente se comprometeu instintivamente com essa teoria, mais por razões estéticas e metafísicas do que empíricas. Isso lembra Copérnico que não tinha argumentos racionais, físicos e matemáticos para defender seu heliocentrismo, mas achava estético um Universo em que todos os planetas fossem iluminados ao mesmo tempo pelo Sol, situado no centro.

Na recém terminada I Guerra, os tempos eram de difícil convivência entre os povos. Havia um pano de fundo de rancor e ressentimento em escala global que separava as Potências Aliadas e as Potências Centrais. E dentro da Alemanha iria rapidamente ganhar ímpeto o nazismo contra a pequena minoria de judeus. Em ambos os casos houve envolvimento da ciência e dos cientistas. Lideranças importantes dos Países Aliados, que contavam com muitos astrônomos, discutiam a formação de organizações internacionais objetivando a paz, tendo em vista que a ordem mundial vigente era desfavorável à atividade científica (OLIVEIRA, 2009) ${ }^{148}$. Essas lideranças, algumas tinham perdido filhos na Guerra, mas todas estavam ofendidas com cientistas e artistas alemães que tinham assinado em 1914 o "Manifesto dos 93" que apoiara as ações belicistas do exército alemão na I Guerra. Dentre os que assinaram estavam o nosso conhecido Max Planck e Phillip Lenard. Einstein foi um dos poucos pacifistas que assinou um Manifesto contrário, opondo-se à entrada da Alemanha na I Guerra.

Nesse contexto tumultuado surgiu a União Astronômica Internacional (IAU) em 1919 que, aliás, também celebra seu centenário este ano. Vimos que quando Campbell participou da sessão da RAS em Londres, em 11/7/1919, ele estava a caminho de Bruxelas. Aí ele participou como representante dos Estados Unidos, de uma reunião entre 18 e 28 de julho, na qual foi fundada a International Research Council (IRC) cujos objetivos eram: facilitar nas Potências Aliadas o intercâmbio entre os cientistas, promover nelas a atuação dos cientistas na indústria e boicotar

147 EARMAN, J. and GLYMOUR, C. Ibid., 1980a, p. 50.

148 OLIVEIRA, Raquel dos Santos. A participação do Observatório Nacional na União Astronômica Internacional: instrumentos da diplomacia (1919-1938), XXV Simpósio Nacional de História, 12-17 de julho de 2009, Fortaleza, CE, ANPUH (Associação Nacional de História), 2009. Disponível em <http://encontro2014.rj.anpuh.org/resources/anais/anpuhnacional/S.25/ANPUH.S25.1233.pdf $>$. Acesso em $16 / 2 / 19$. 
as Potências Centrais. A IRC restringia o ingresso das Potências Centrais e procurava isolar a Alemanha. Nesse sentido, a IRC não era, de fato, uma organização internacional. Nem era verdadeiramente internacional a IAU que seguiu inicialmente as diretrizes da IRC. Na esteira da animosidade geral contra a Alemanha, a ciência desenvolvida naquele país, se ruim deveria ser vista com desconfiança; se boa era considerada subproduto do trabalho de estrangeiros que lá estavam ou, então, plágio da boa ciência feita fora. Um caráter internacional começou a ser implantado em 1931, quando a IRC deu lugar ao International Council of Scientific Unions. Mas o ingresso da Alemanha na IAU só ocorreu em 1951. Olhando hoje para as relações internacionais na Astronomia, fica claro que esses ressentimentos entre os astrônomos ficaram definitivamente no passado.

Mas dentro da Alemanha, onde o nazismo recrudescia, Einstein e a Relatividade se tornaram alvo de ataques por causa do antissemitismo. A Relatividade foi tachada pejorativamente como "ciência judaica". Em 1920, o alemão antissemita Paul Weyland (1888-1972), que hoje seria considerado marqueteiro, organizou um forum público para denunciar Einstein e sua teoria de estarem envenenando a cultura alemã.

Aquele cálculo da deflexão gravitacional da luz publicado por Soldner em 1803 foi redescoberto após um século de esquecimento pelo físico alemão da área de Óptica, E. Lihotzki que, tendo lido o texto de Eddington de 1918 sobre a Relatividade, resolveu comparar a predição da deflexão de Einstein com a predição de Soldner (JAKI, 1978, p. 930) ${ }^{149}$. No fim Lihotzky publicou um artigo ${ }^{150}$ de ataque a Einstein com argumentos débeis e acusando a Relatividade de se basear em hipóteses complicadas que tangenciavam contradições. Mas o problema estava mais no entendimento insuficiente de Lihotzki do que na teoria de Einstein.

O já citado Prêmio Nobel de Física de 1905, Philipp Lenard (1862-1947) por suas pesquisas em raios cósmicos, também antissemita e um dos líderes da cruzada anti-Einstein ${ }^{151}$, ficou sabendo através de colegas acadêmicos do cálculo de Soldner publicado no artigo de Lihotzky. Logo ele se aproveitou desse artigo e fez uma publicação ${ }^{152}$ tentando imputar a Einstein o crime de plagiar o trabalho de Soldner e argumentando que a predição de Einstein, de fato, não acrescentava nada relevante sobre a predição newtoniana, além de que esta era mais simples como são todas as boas teorias, de modo que a teoria de Einstein era desnecessária. Foi através desta publicação de Lenard, em que ele diminui o mérito e a pessoa de Soldner e traduz seu artigo

149 JAKI, Stanley L. Ibid., 1978, p. 930.

${ }^{150}$ LIHOTZKY, E. Zur Frage der Verschiebung der scheinbaren Fixsternorte in Sonnennähe, Physikalische Zeitschrift, v. 22, 69-71, 1921.

151 Outro físico alemão que participou da cruzada antissemita foi Johannes Stark (1874-1957), Prêmio Nobel de Física de 1919, conhecido pelo efeito que leva o seu nome.

152 LENARD, P. Über die Ablenkung eines Lichtstrahls von seiner geradlinigen Bewegung durch die Attraktion eines Weltkörpers, an welchem er nahe vorbeigeht; von J. Soldner, 1801. Mit einer Vorbemerkung von P. Lenard, Annalen der Physik, v. 65, 593-604, 1921. 
apenas parcialmente, que Jaki tomou conhecimento do trabalho original de Soldner e o traduziu integralmente ao inglês (JAKI, 1978, 939-948) ${ }^{153}$.

A cruzada antissemítica ainda patrocinava palestras, queima de livros e publicação de outros com ataques grosseiros à Relatividade e Einstein, além de obras difamatórias como Hundert Autoren gegen Einstein (Cem autores contra Einstein) de 1931. No fundo essa obra era preconceituosa e as críticas punham mais em evidência a incapacidade do entendimento correto da Relatividade. Segundo o físico-matemático canadense Clifford M. Will (1946-), especializado em testes experimentais da Relatividade Geral, a vasta maioria dos físicos alemães não compartilhava desses sentimentos antissemíticos e, apesar do crescente nazismo e consequente demissão e emigração de muitos físicos judeus (inclusive Einstein), o programa Anti-Relatividade terminou como pouco mais do que uma nota de rodapé na História da Ciência (WILL, 2015, p. 5) ${ }^{154}$.

Sucesso medíocre das novas análises e observações

Segundo WILL (1988, p. 5) ${ }^{155}$, entre 1923 e 1956 as placas do eclipse utilizadas por Eddington foram reanalisadas inúmeras vezes por causa de possível viés pela simpatia que ele nutria pela Relatividade e Einstein. Mas essas análises teriam sempre reproduzido os mesmos resultados dentro de 10\%. Em 1979, por ocasião do centenário do nascimento de Einstein, astrônomos do Real Observatório de Greenwich reanalisaram os dois conjuntos das placas de Sobral numa moderna máquina medidora Astrorecord Zeiss de dois eixos X-Y com o respectivo software (HARVEY, 1979) ${ }^{156}$. Das placas do telescópio de 4 polegadas se obteve virtualmente o mesmo resultado obtido anteriormente, com o erro reduzido em $40 \%$. Das placas do telescópio astrográfico, não medindo mais os desvios como antes para cada par de placas do eclipse e de comparação, mas para cada placa do eclipse em relação às posições resultantes da combinação de todas as placas de comparação, se obteve 1,55” \pm 0,34” no limbo, um valor agora consistente com a Relatividade Geral, mas afetado de grande erro. Esse resultado é bastante discrepante em relação ao resultado original de 0,93 ” que era favorável à teoria newtoniana. A meu ver, este resultado mostra a alta instabilidade dos dados a pequenas variações do método, o que é um resultado ruim, enquanto os outros parecem ratificar, não o procedimento adotado, mas apenas os cálculos numéricos. KENNEFICK (2009, p. 42) $)^{157}$ que valorizou muito os resultados dessa

153 JAKI, Stanley L. Ibid., 1978, 939-948.

154 WILL, Clifford M. Ibid., 2015, p. 5.

155 WILL, Clifford M. Ibid., 2015, p. 5.

156 HARVEY, Geoffrey M. Gravitational deflection of light: A re-examination of the observations of the solar eclipse of 1919, The Observatory, 99, 195-98, 1979.

157 KENNEFICK, Daniel. Ibid., 2009, p. 42. 
reanálise, justificou a exclusão das placas astrográficas de Sobral, contudo, JONES e KAISER (2010) $)^{158}$ argumentaram longamente refutando essa justificação.

Após o "sucesso" de Eddington, sete equipes tentaram refazer as observações no eclipse de 21/9/1922 na Austrália, mas só três equipes foram bem-sucedidas. Uma das que não teve sucesso foi a equipe britânica, sendo que os próprios britânicos tinham sugerido a obtenção da confirmação da deflexão nesse eclipse. Eles se instalaram em Christmas Island onde o céu esteve nublado durante o eclipse (CAMPBELL, 1923, p. 19-20) ${ }^{159}$. Dentre as equipes que tiveram êxito, uma era a americana, do Observatório de Lick, outra canadense e outra, anglo-australiana. Desta última participou Davidson que também tinha estado em Sobral. Como os australianos não tinham os instrumentos, uma parte (um excelente quadrupleto de 4,1 polegadas, diafragmado para 3 polegadas e com foco de 64,2 polegadas) foi emprestada por Curtis, diretor do Observatório de Allegheny e outra parte (montagem para a câmara, relógio para acionamento do telescópio etc.) por Campbell, diretor do Observatório de Lick. O local de observação foi Cordillo Downs, no sul da Austrália. Foram obtidas 13 placas de eclipse e 7 de comparação e 14 estrelas foram medidas. A deflexão no bordo obtida foi 1,73" $\pm 0,3$ ” (DODWELL and DAVIDSON, 1924) ${ }^{160}$, mas com incerteza grande.

A equipe de Campbell e Robert Julius Trumpler (1886-1956), ambos do Observatório de Lick, anunciou uma deflexão no limbo solar de 1,72" $\pm 0,11$ " (excelente resultado face à predição de 1,75”). Essa equipe se instalou em Wallal, uma estação de telégrafo no noroeste da Austrália, e fez uma esmerada preparação, pois uma boa observação da deflexão de Einstein tinha se tornado um ponto de honra institucional para Campbell: Feeling that our pioneer efforts in 1914 and 1918 had placed a serious responsibility upon us, I decided ... in favor of an Einstein equipment for use at Wallal... (CAMPBELL, 1923, p. 20) ${ }^{161}$. Além de muitos equipamentos para observações em Física Solar, para observar o efeito Einstein a equipe de Lick construiu e levou um par de câmaras tendo como objetiva um quadrupleto (justaposição de 4 lentes desenhada para minimizar aberrações ópticas) de 5 polegadas e foco de 15 pés, mais outro par de câmaras com quadrupleto de 4 polegadas e foco de 5 pés, este último para observar a região mais próxima ao Sol. As câmaras estavam presas a uma montagem equatorial. Assim o uso de espelho foi eliminado. $\mathrm{O}$ campo visual do primeiro par de câmaras era grande, com raio de cerca de $2,5^{\circ}$, de modo que muitas estrelas (cerca de 100) cabiam na placa, o que tornava a análise estatística mais confiável. As estrelas a mais de $2^{\circ}$ do centro do disco solar podiam servir de referência porque a essas

158 JONES, David and KAISER, David. A Study Eclipsed by Confirmation Bias, MIT OpenCourseWare STS.003 The Rise of Modern Science, 2010. Disponível em <https://ocw.mit.edu/courses/sciencetechnology-and-society/sts-003-the-rise-of-modern-science-fall-2010/assignments/assn4a/ MITSTS_ 003F10_assn4_a1.pdf $>$. Acesso em 19/1/2019.

${ }_{159}$ CAMPBELL, W. W. Ibid., 1923, pp. 19-20.

160 DODWELL, G. F. and DAVIDSON, C. R. Determination of the Deflection of Light by the Sun's Gravitational Field from Observations made at the Cordillo Downs, during the Total Eclipse of 1922 September 21, Monthly Notices of the Royal Astronomical Society, 1924, v. 84, n. 3, 150-162.

161 CAMPBELL, W. W. Ibid., 1923, p. 20. 
distâncias a deflexão da luz se tornava desprezível. Para os ótimos resultados obtidos foram utilizadas 4 placas que foram analisadas com placas de comparação e de verificação obtidas no mesmo posto de observação do eclipse e, uns 5 meses antes em Taiti (CAMPBELL and TRUMPLER, 1923) ${ }^{162}$. Em tom de alívio Campbell anunciou que tinha obtido um resultado que concordava exatamente com a predição de Einstein e essa observação foi muitas vezes considerada a confirmação cabal e inconteste dos resultados de Eddington. Foi também a última expedição de Campbell a um eclipse: The last eclipse expedition was important, as it confirmed Einstein's prediction that starlight would be deflected by the Sun's gravity. Many scientists had accepted the results of Arthur S. Eddington and Frank W. Dyson at the 1919 eclipse, but Robert Trumpler's measurements of the Australia plates made by bimself and Campbell three years later had much smaller uncertainties (TENN, 1992, p. 75) ${ }^{163}$.

No entanto, nem mesmo as excelentes medidas de Campbell e Trumpler encerraram a questão. Novas medições em eclipses continuaram sendo feitas por mais de meio século. Em geral elas corroboravam a Relatividade Geral, deixando pouca dúvida de que a predição de Einstein era a correta, não a de Newton. Mas, surpreendentemente, houve pouca melhora na precisão que nunca passou de um fator 2, e que confirmava a previsão relativística dentro de uma incerteza de 10\%. A deflexão medida variava entre 75 e 150\% do valor teoricamente esperado.

Em 1931, portanto tardiamente, surgiu na Alemanha uma reação hostil ao anúncio de Eddington desferida pelo nosso conhecido Freundlich (ALMASSI, 2009, p. 65) ${ }^{164}$. Depois de realizar várias expedições entre 1914 e 1926, nas quais fracassou por causa da chuva ou da Guerra, finalmente ele conseguiu observar o eclipse de 9/5/1929 na Sumatra do Norte, Indonésia, que então era holandesa. Apesar de ter tomado a cautela de incorporar um controle direto para a variação de escala da placa, projetando uma rede no campo de visão do telescópio, Freundlich obteve uma deflexão no limbo solar de 2,24 ” $\pm 0,10$ ”, muito discrepante do valor relativístico, como também do resultado de Eddington. Após criticar os procedimentos utilizados por Eddington na redução dos dados de 1919, apresentou o resultado corrigido por ele em que a deflexão média seria próxima de 2,2" quando também desqualificou a predição de Einstein. Freundlich não recebeu apoio dos físicos, astrofísicos e astrônomos e, pateticamente, a objeção dele caiu no vazio na Grã-Bretanha.

Merece destaque a expedição organizada pela Universidade do Texas em Austin para observar o eclipse de 30/6/1973 no Oásis Chinguetti, na Mauritânia (TEXAS MAURITANIAN

162 CAMPBELL, W. W. and TRUMPLER, R. Observations on the deflection of light in passing through the Sun's gravitational field, Lick Observatory Bulletin, v. 11, n. 346, 41-54, 1923.

163 TENN, Joseph S. Wallace Campbell: The Twelfth Bruce Medalist, in Bruce Medalist Profiles, Mercury, March/April, 62-75, 1992, p. 75.

164 ALMASSI, Ben. Ibid., 2009, p. 65. 
ECLIPSE TEAM, 1976) ${ }^{165}$. Essa expedição contou com novos recursos tecnológicos, tais como: modernas emulsões fotográficas, controle da temperatura no abrigo do telescópio, sofisticados motores para o apontamento preciso do telescópio, análise computadorizada das fotografias. Todavia não foi possível controlar os ventos que levantaram poeira e reduziram severamente a visibilidade e a quantidade de imagens tomadas. Uma nova expedição retornou ao mesmo local cinco meses depois para obter as imagens de comparação. As medições foram feitas numa máquina moderna em Greenwich, mas o resultado não trouxe nenhum avanço na precisão em relação às observações anteriores. Obteve-se uma deflexão no limbo igual a 0,95 ” $\pm 0,11$ ” (WILL, 2015 p. 6) ${ }^{166}$.

Aqui no Brasil a observação do efeito Einstein foi tentada no eclipse solar de 6/11/1966 em Bagé, RS, por uma equipe liderada por Abrahão de Moraes (1917-1970), então diretor do IAG/USP e Presidente da Comissão de Organização da Comissão Nacional de Atividades Espaciais, atual Instituto Nacional de Pesquisas Espaciais (INPE), em São José dos Campos, SP. Da equipe participaram José Antonio de Freitas Pacheco (Observatoire de la Côte d'Azur), Germano R. Quast (Laboratório Nacional de Astrofísica/Itajubá, MG) e Rodolpho Vilhena de Moraes (UNIFESP/São José dos Campos, SP), todos na época ligados ao Instituto Tecnológico de Aeronáutica (ITA) em São José dos Campos, SP. Quast retornou para Bagé cerca de seis meses depois para obter as placas de comparação. Segundo pude apurar, os dados foram analisados por Quast que os teria aproveitado para o seu trabalho de formatura no ITA.

No eclipse anterior de 20/5/1947, o IAG/USP que instalou os equipamentos em Bebedouro, SP, pretendeu observar, dentre outros fenômenos, o efeito Einstein, mas foi impedido por causa de chuva (MARQUES DOS SANTOS, 2005, p. 111-112) ${ }^{167}$. O astrônomo belga naturalizado americano, George Van Biesbroeck (1880-1974), do Observatório de Yerkes, da Universidade de Chicago, já estava aposentado, mas se instalou em Bocaiúva, MG, para observar o efeito Einstein. Van Biesbroeck usou um telescópio com tripleto de 3 polegadas e foco de $6 \mathrm{~m}$. Para bem determinar a escala da placa, acoplou um engenhoso sistema com placa de vidro semiespelhado que alimentava a objetiva ao mesmo tempo com duas imagens, uma do campo estelar do eclipse e outra de um campo estelar mais afastado. Davidson, desta vez aquele que tinha vindo a Sobral, já antecipava dificuldades para o eclipse de 1922 pelo fato de que havia poucas estrelas brilhantes nas proximidades do disco solar, e advogou essa técnica usada por Van Biesboeck para remover o efeito sistemático da variação de escala das placas, uma vez que os campos do eclipse e de verificação eram obtidos simultaneamente, nas mesmas condições (DAVIDSON,

165 TEXAS MAURITANIAN ECLIPSE TEAM, Gravitational deflection of light: solar eclipse of 30 June 1973 I. Description of procedures and final results, Astronomical Journal, v. 81, n. 6, 1976, 452-454.

166 WILL, Clifford M. Ibid., 2015, p. 6.

${ }^{167}$ MARQUES DOS SANTOS, Paulo. Instituto Astronômico e Geofísico da USP. Memória sobre sua Formação e Evolução. São Paulo: EDUSP, 2005, p. 111-112. 
1922) ${ }^{168}$. A vantagem era que no interior do telescópio as duas imagens percorriam o mesmo trajeto óptico (VAN BIESBROECK, 1950) ${ }^{169}$. Van Biesbroeck voltou a Bocaiúva em agosto daquele ano para obter as imagens de comparação. O resultado que ele obteve foi 2,01" $\pm 0,27$ ”.

O anúncio da confirmação da deflexão da luz em 1919 provocou não só a busca de confirmações desse efeito, como também de uma outra predição da Relatividade Geral: o deslocamento gravitacional de linhas espectrais para o vermelho. Mas como medições confiáveis e confirmações empíricas contundentes deste efeito não vieram até a década de 1960, houve um declínio contínuo do interesse científico pela Relatividade Geral. Esse panorama mudará nos anos 1960 com o avanço das "tecnologias de precisão", graças ao surto de desenvolvimento instrumental, o início do programa espacial (fruto da II Guerra) e o advento dos computadores (WILL, 2015, p. 2) $)^{170}$.

\section{Tecnologias de precisão. Supercomprovação}

Os três testes clássicos para a comprovação da Teoria da Relatividade Geral foram propostos em relação a três efeitos da gravidade: 1) o deslocamento de linhas espectrais para o vermelho; 2) a deflexão da luz (tema central deste texto) e 3) o deslocamento anômalo do periélio dos planetas (o de Mercúrio se tornou importante porque esse efeito, maior porque esse planeta está mais perto do Sol, foi historicamente descoberto em 1843 por Urbain Jean Joseph Le Verrier (1811-1877). De acordo com a teoria de Newton, o deslocamento do periélio de Mercúrio era devido à atração gravitacional dos outros planetas, mas as observações mostravam uma discrepância a mais de 43"/ século que essa teoria não explicava. Nenhum dos três efeitos pode ser explicado com a teoria de Newton. Diferentemente dos dois primeiros, este último foi proposto por Einstein em 1915 para explicar uma anomalia que já era conhecida.

Um avanço espetacular ocorreu em 1967 (LONGAIR, 2015, pp. 9-10) ${ }^{171}$ como desdobramento do advento da radioastronomia (fruto da tecnologia de radares da II Guerra) em 1932. A partir de então, o Universo passou a ser observado não só na luz visível, mas também através de ondas de rádio. Em 1967 se descobriu que, com medições simultâneas feitas com vários radiotelescópios distribuídos sobre o globo usando a técnica de interferometria VLBI (Very Long Baseline Interferometry), podia-se medir a deflexão das ondas eletromagnéticas com precisão da

168 DAVIDSON, C. Observation of the Einstein Displacement in Eclipses of the Sun, The Observatory, v. 45, 1922, 224-224.

169 VAN BIESBROECK, G. The Einstein shift at the eclipse of May 20, 1947, in Brazil, The Astronomical Journal, v. 55, 1950, 49-52.

170 WILL, Clifford M. Ibid., 2015, p. 2.

171 LONGAIR, Malcolm. Bending space-time: a commentary on Dyson, Eddington and Davidson (1920) 'A determination of the deflection of light by the Sun's gravitational field', Philosophical Transactions of the Royal Society A, v. 373, 20140287, 1-13, 2015, pp. 9-10. 
ordem de 0,001". Para simples comparação, por causa do fenômeno da cintilação causada pela turbulência atmosférica, a posição de uma estrela na luz visível é afetada por uma incerteza típica da ordem de 1". Agora a precisão das medidas era mil vezes melhor. Com a técnica VLBI podem ser usadas, em vez de estrelas de fundo da nossa própria Galáxia, os quasares que são astros extragalácticos de aparência pontual. Suas distâncias cosmológicas asseguram maior estabilidade posicional dessas referências. É impressionante constatar como a incerteza das medidas foi sendo reduzida drasticamente desde 1970, quando avanços tecnológicos importantes ocorreram $^{172}$, sendo que agora ela é da ordem do décimo de milésimo da deflexão predita por Einstein. Assim, para centenas de rádio-fontes a deflexão foi medida e a predição de Einstein veio sendo confirmada.

Como se não bastasse, a mesma técnica radioastronômica possibilita ainda uma verificação adicional não predita por Einstein, mas com o mesmo grau de precisão, na qual é medido na Terra, não o desvio angular da radiação, mas o atraso temporal de um sinal de radar transmitido da Terra para um satélite artificial onde um transponder transmite um sinal de volta para a Terra. Durante o experimento o sinal de radar se propaga através do campo gravitacional do Sol. Esse atraso do sinal é conhecido como efeito Shapiro porque o radioastrônomo americano Irwin Ira Shapiro (1929-), professor da Universidade de Harvard, propôs e realizou a verificação desse fenômeno.

Hoje a questão não é mais confirmar a deflexão gravitacional da luz. Ela é uma certeza que deu lugar a um novo recurso observacional que potencializa exponencialmente a capacidade dos nossos telescópios. A deflexão da luz, quando ocorre em massas muito, muito maiores do que a de uma estrela como o Sol, digamos, a massa de uma galáxia ou de um aglomerado de galáxias, produz deflexões angulares mais pronunciadas sobre a luz, alterando a forma e o brilho da imagem de um objeto cosmológico que esteja atrás e praticamente alinhado em relação a nós na Terra. Várias imagens do Telescópio Espacial Hubble de quasares distantes que assumem forma de anel ou de cruz, ou que ganham duplicidade, resultam do fenômeno cósmico natural agora chamado com total propriedade lente gravitacional, pois, de fato, a deflexão gravitacional da luz por massas muito grandes, pode produzir intensificação da imagem, à semelhança das lentes dos telescópios ópticos. Há também as microlentes gravitacionais causadas por massas menores,

${ }^{172} \mathrm{Na}$ História da Astronomia é perceptível que os avanços na instrumentação estão correlacionados com o deslocamento da Astrofísica para os Estados Unidos, onde os maiores telescópios do mundo na época possibilitaram a descoberta da expansão do Universo por Edwin Hubble (1889-1953). Lá teve início também a radioastronomia e engenheiros da Bell Telephone Laboratories descobriram em 1964 a Radiação Cósmica de Fundo em micro-ondas. Durante a competição com a União Soviética pela conquista do espaço, lá também foi desenvolvida a engenharia espacial que desenvolve programas astronômicos com observatórios e sondas espaciais. 
como de estrelas, que também são úteis porque permitem observar objetos com massa intermediária entre a massa de um planeta e a massa de uma estrela. Portanto a deflexão da luz nos brindou com as inestimáveis lentes gravitacionais como nova ferramenta que já se tornou usual para observações da massa e estrutura de galáxias e quasares distantes, de objetos cosmológicos de grande escala, como também de exoplanetas orbitando estrelas distantes. As lentes podem ser usadas também como balanças para medir a massa de objetos astronômicos.

Embora a deflexão da luz fosse sendo gradativamente aceita como um sucesso da Relatividade Geral, o deslocamento para o vermelho de linhas espectrais pela ação da gravidade nunca foi medido de forma conclusiva até a década de 1960. E esse efeito tinha sido predito por Einstein em 1911! Em 1917 tinha sido anunciado que tal deslocamento não tinha sido observado no espectro do Sol e em 1918 que as observações tinham sido inconclusivas (WILL, 2015, p. $6)^{173}$. Isso estabeleceu um quadro negativo que perdurou décadas e que, às vezes, serviu de alegação para se duvidar da Relatividade Geral, o que tornava difícil justificar novas expedições para tentar confirmar a deflexão einsteiniana da luz. Então teria ocorrido também um arrefecimento do interesse pela Relatividade, que se refletiu inclusive num decréscimo de publicações sobre esse assunto após um surto inicial. Isso ficou espelhado também na criação em 1922 da Comissão 1 da IAU sobre Relatividade, sob a coordenação de Eddingtton, e sua extinção já em 1925. Em 1922 o já citado Whitehead chegou a elaborar uma teoria alternativa da gravidade que mantinha o espaço-tempo plano da Relatividade Restrita, mas incluía um tensor que, através de uma "ação a distância”, causava a deflexão da luz predita por Einstein e o movimento orbital da matéria, mas não previa o deslocamento espectral para o vermelho.

Mas é preciso considerar que a medição do deslocamento espectral no Sol não é uma tarefa trivial. O espectro do Sol sofre o chamado "efeito centro-limbo" pelo qual o efeito Doppler sofrido pelas linhas espectrais, devido aos complexos movimentos turbulentos e convectivos do gás na baixa atmosfera solar, visto da Terra aparenta ser menor no bordo do que no centro do disco solar, já que no bordo esses movimentos são predominantemente transversais à linha de visada. Para contornar essa dificuldade era preciso escolher no espectro linhas intensas e com as quais a medição do comprimento de onda pudesse ser feita sem ambiguidade. Mas medidas confiáveis só começaram a ser obtidas a partir da década de 1960, não observando linhas do espectro do Sol, mas de anãs brancas cuja gravidade na superfície é muito mais intensa. $\mathrm{Na}$ mesma década o efeito foi confirmado num experimento terrestre, com a variação da gravidade numa diferença de altura de apenas $23 \mathrm{~m}$ ! Obviamente foi utilizada uma linha espectral especial. Hoje em dia esse efeito não pode deixar de ser levado em conta no sistema de posicionamento global, GPS, a fim de que opere corretamente.

173 WILL, Clifford M. Ibid., 2015, p. 6. 
Assim todos os testes clássicos da Relatividade Geral foram definitivamente confirmados. Dizem que a Relatividade Geral não é uma teoria correta da gravidade por não ser quântica. Em todo o caso, ela subministrou os fundamentos teóricos para explicar a origem e evolução do Universo através da conhecida Cosmologia do Big Bang. Mas isso é um outro assunto.

\section{Considerações finais}

Para celebrar o centenário da Relatividade Geral em 2015, o já citado Clifford Will, conhecido por seus importantes estudos sobre a irradiação de ondas gravitacionais por pulsares binários, escreveu um artigo (WILL, 1915) ${ }^{174}$ em que exaltou os resultados do eclipse de 1919 por terem legado um fecundo programa de testes experimentais que prossegue até hoje confirmando a deflexão gravitacional da luz com ondas de rádio, nos revelando as lentes e as ondas gravitacionais. A avaliação é positiva e o artigo termina assim: Even if some modified version of general relativity must be adopted ultimately to accommodate new observations, the theory that caused such a sensation in 1919 will very likely still be its foundation.

Nesse mesmo ano o professor de Filosofia Natural da Universidade de Cambridge, Malcolm Longair (1941-) escreveu um artigo (LONGAIR, 2015) ${ }^{175}$ para comemorar o $350^{\circ}$ aniversário da Phylosophical Transactions of the Royal Society. Longair que inclui nos seus interesses de pesquisa a Cosmologia e, mais recentemente, passou a incluir também a história científica da Física, Astronomia, Astrofísica e Cosmologia, escolheu para esse artigo comentar o artigo histórico de DYSON, EDDINGTON e DAVIDSON (1920) ${ }^{176}$ sobre as observações do eclipse de 1919. A avaliação inteiramente positiva, assim como a abordagem do tema é impressionantemente a mesma do artigo anterior de Will. De fato, é inconteste que o eclipse de 1919 imprimiu ímpeto com o qual boa parte da ciência, ainda hoje, oferece fantásticos desdobramentos.

Mas a avaliação puramente positiva, embora compreensível, fecha os olhos para falhas objetivas, possivelmente porque seja a visão daqueles que, em sua atividade profissional, mais percebem os avanços conquistados posteriormente e mais se beneficiam deles. Apesar dos pecadilhos e das falhas próprias da condição humana, objetivamente a Revolution in Science teria inaugurado uma era de substanciais avanços científicos. Talvez, até mesmo graças a esses pecadilhos e falhas, tudo no fim teria dado certo!

Já os filósofos da ciência americanos, John Earman (1942-) da Universidade de Pitsburgo, na Pensilvânia, e Clark N. Glymour (1942-) da Universidade Carnegie Mellon também

174 WILL, Clifford M. Ibid. 2015.

175 LONGAIR, Malcolm. Ibid. 2015.

176 DYSON, F. W., EDDINGTON, A. S. and DAVIDSON, C. Ibid., 1920. 
em Pitsburgo (EARMAN and GLYMOUR, 1980a) ${ }^{177}$; (EARMAN and GLYMOUR, 1980b) ${ }^{178}$, ambos citados antes inúmeras vezes, fizeram uma análise crítica do próprio trabalho científico de Eddington e seus colaboradores, ou seja, puseram a mão na ferida. O jornalista científico norte-americano, Dennis Overbye (1944-), citado num artigo crítico de SOARES (2006) ${ }^{179}$, também argumentou nessa linha (OVERBYE, 2000) ${ }^{180}$. Já citei Earman e Glymour antes, quando eles apontaram para uma inconsistência na derivação de Einstein, de 1915, da deflexão da luz. Mas eles também argumentaram que houve uso (ou abuso) de autoridade acadêmica (magister dixit) por parte de Eddington quando anunciou a confirmação do efeito Einstein. Eles também criticaram o descarte das observações astrográficas de Sobral que eram desfavoráveis à teoria de Einstein, ao mesmo tempo em que não descartaram as escassas e imperfeitas imagens de Príncipe. Para sustentar esta última crítica, EARMAN e GLYMOUR (1980a, p. 75) ${ }^{181}$ converteram o erro provável de Eddington em desvio padrão. Para as placas de Sobral com o telescópio de 4 polegadas obtiveram deflexão no limbo solar de 1,98 " \pm 0.178" e com o astrógrafo, $0,86 " \pm$ 0,48”. Para as placas do astrógrafo de Príncipe obtiveram 1,61" $\pm 0,444$ ”. Daí concluíram que a dispersão das placas do astrógrafo de Príncipe e de Sobral eram praticamente equivalentes. Por isso eles não encontraram razões objetivas para o descarte das placas de Sobral, sem que as de Príncipe também fossem descartadas.

Já as imagens de Sobral com o telescópio de 4 polegadas tinham boa qualidade e baixa dispersão, mas o valor médio (1,98”) era significativamente maior (1,3 vezes o desvio padrão) que a predição de Einstein, portanto não constituía uma confirmação inequívoca da predição de Einstein. Mantendo todas as placas, a deflexão estaria entre 0,87 ” e 2", o que não decidiria entre o valor einsteiniano ou newtoniano (EARMAN and GLYMOUR, 1980a, 75-76) ${ }^{182}$. Logo, os resultados obtidos não eram inequivocamente favoráveis à predição de Einstein. Mesmo assim, Dyson afirmou que a predição de Einstein tinha sido confirmada.

As críticas objetivas de Earman e Glymour mostram que, mesmo que Eddington tenha procurado se pautar pela racionalidade, prudência e boa-fé, estimulado por excessiva autoconfiança acabou se expondo, ainda que involuntariamente, a riscos temerários. Mas contou com toda sorte do mundo ao escolher a predição einsteiniana já que, com o tempo, a Relatividade Geral foi convalidada. Correr riscos é a vocação dos que anunciam o que até então é desconhecido, mas é a sorte que separa os vitoriosos dos fracassados.

177 EARMAN, J. and GLYMOUR, C. Ibid., 1980a.

178 EARMAN, John and GLYMOUR, Clark Ibid., 1980 b.

179 SOARES, Domingos S. L. A real importância de Sobral na ciência moderna. Boletim da Sociedade Astronômica Brasileira, v. 25, n. 2, 21-29, 2006.

180 OVERBYE, Dennis. Einstein in love: a scientific romance. New York: Viking Press, 2000.

181 EARMAN, J. and GLYMOUR, C. Ibid., 1980a, 75.

182 EARMAN, J. and GLYMOUR, C. Ibid., 1980a, pp. 75-76. 
Que Eddington teve sorte fica evidente diante de meio século de novas tentativas que não conseguiram reduzir significativamente a incerteza da deflexão da luz. Fica evidente também diante do grande equívoco em que ele se enredou anos depois, quando supostamente ele deveria ter acumulado mais experiência e sabedoria. Em 1935 ocorreu a famosa controvérsia entre ele e o promissor jovem indiano, depois famoso astrofísico da Universidade de Chicago, Subrahmanyan Chandrasekhar (1910-1995). Desta vez a controvérsia foi acerca do limite superior (valor máximo) da massa das estrelas anãs brancas ${ }^{183}$, limite esse que hoje é matéria de livros-texto de Astrofísica. Essa controvérsia envolvia uma questão teórica ao combinar a Relatividade Restrita com a Mecânica Quântica na Mecânica Estatística. Ela foi tema de uma interessante tese doutoral em História da Ciência pela University College London (GOONERATNE, 2005) ${ }^{184}$. Eddington, um relativista convicto, rejeitou a formulação de Chandrasekhar para descrever o comportamento dos elétrons, literalmente esmagados no interior denso das anãs brancas, utilizando Mecânica Quântica e Relatividade Restrita, esta última porque a alta densidade implicava reduzidíssimo espaço para cada elétron e, consequentemente, velocidades microscópicas relativísticas, consequência do Princípio da Incerteza. Eddington desacreditava dessa mestiçagem com tal autoconfiança (a mesma que ele tinha em relação à deflexão da luz), que a sustentou até sua morte, em 1944. Segundo Chandrasekhar, a alta compressão dos elétrons implicava em que, quanto maior a massa da anã branca, menor ficava o seu raio ao se colapsar gravitacionalmente. O Limite de Chandrasekhar era a massa com a qual a anã branca ficava com raio nulo, uma singularidade matemática. A rejeição instintiva a singularidades era uma razão a mais para Eddington rejeitar o Limite de Chandrasekhar. Para ele, singularidades eram meros entes matemáticos, sem correspondência com o mundo real. Com esses argumentos Eddington rechaçaria também os buracos negros. Para ele a natureza tinha que ter leis que interditassem tais despautérios.

No entanto, Chandrasekhar estava certo. Não obstante ele foi moralmente esmagado pela superautoridade de Eddington, então amplificada pela confirmação da deflexão da luz no eclipse de 1919. Até mesmo físicos da estatura de Niels Bohr (1885-1962) e Wolfgang Pauli (1900-1959) não ousaram desafiar tal autoridade que, portanto, se sustentava bilateralmente.

Voltando às análises do anúncio de 1919, os sociólogos britânicos da ciência, Harry Collins (1943-) e Trevor J. Pinch (1952) acusaram Eddington de ter manipulado os resultados

183 Anãs brancas são estrelas muito densas (embora não as mais densas), tipicamente com massa comparável à do Sol, mas comprimida num volume como o da Terra, de modo que a densidade típica é cerca de 1 ton/cc. Essa compressão ocorre quando uma estrela com massa inicial não superior a 10 massas solares, esgota seu combustível nuclear (hidrogênio, hélio etc.) e colapsa gravitacionalmente. Esse deve ser o futuro do nosso Sol. A massa das anãs brancas não pode exceder cerca de 1,44 vezes a massa do Sol e esse limite é conhecido como Limite de Chandrasekhar. Isso implica também em que, ao entrar na fase terminal, as anãs brancas precisam descartar parte considerável de sua massa inicial.

184 Gooneratne, Sakura. The White Dwarf Affair: Chandrasekhar, Eddington and the Limiting Mass, Ph. D. Thesis on Philosophy in the History of Science, University College London, University of London, London, 2005. 
para produzir os resultados preditos por Einstein (COLLINS and PINCH, 1993) ${ }^{185}$. Agora não é apenas uma crítica, mas uma acusação que envolve conduta ética. Na mesma linha, o já citado pesquisador da University College London em História da Medicina, John Waller, considerado um revisionista iconoclasta de herois ou super-herois da ciência como Pasteur, Mendel etc., acusou Eddington de manipulações e fraudes (WALLER, 2002b)186: Arthur Eddington "proved" Einstein's theory of relativity, and was fortunate enought to be later found correct, even though be suppressed more than twothirds of the eclipse photographs on which his proof was based.

Prefiro passar ao largo do julgamento de intenções, pois são inacessíveis, assim como do julgamento da conduta em atos de 100 anos atrás pelo risco de julgamentos anacrônicos face à mudança constante e veloz da valoração atribuída à ciência e à atividade científica, dos referenciais éticos e das posturas, sem falar dos pormenores de contexto que nos escapam. Mas considero válida e bem-vinda a contribuição da SSK enquanto desmascara supergênios ou a aparência de pura racionalidade ou de assepsia da ciência. Contudo, uma argumentação que considere só os fatores sociológicos, ignorando a dinâmica própria do conhecimento científico que se sustenta pelo diálogo constante entre teoria, que é uma malha complexa de conceitos, postulados e generalizações, com outra malha complexa de experimentos, também é inaceitável.

Diante da variedade de abordagens, um meio termo parece salutar. Não a visão puramente benevolente e otimista, nem a visão pessimista, quase de que a ciência não passa de uma ilusão. Nem mitos falsos de super-heróis, nem niilismo científico, mas transparência pública mostrando a ciência e as atividades científicas simplesmente como elas são.

\section{Agradecimentos}

Sou muito grato às sempre solícitas bibliotecárias Katia Teixeira dos Santos, do Observatório Nacional e Rosa Maria Silva Santos, do IAG/USP.

185 COLLINS, Harry and PINCH, Trevor, The Golem: what everyone should know about science. Cambridge: Cambridge University Press, Chapter 2. Two experiments that 'proved' the theory of relativity, 1993, 27-55.

186 WALLER, John, Einstein's Luck: The truth behind some of the greatest scientific discoveries. Oxford: Oxford University Press, 3. The eclipse of Isaac Newton: Arthur Eddington's 'proof of general relativity, Part 1. Right for the wrong reasons, 2002b. 